\title{
Grain-size sorting in grainflows at the lee side of deltas
}

\author{
MAARTEN G. KLEINHANS \\ Department of Physical Geography, Faculty of Geosciences, Universiteit Utrecht, PO Box 80115, 3508 TC \\ Utrecht, The Netherlands (E-mail: m.kleinhans@geog.uu.nl)
}

\begin{abstract}
The sorting of sediment mixtures at the lee slope of deltas (at the angle of repose) is studied with experiments in a narrow, deep flume with subaqueous Gilbert-type deltas using varied flow conditions and different sediment mixtures. Sediment deposition and sorting on the lee slope of the delta is the result of (i) grains falling from suspension that is initiated at the top of the delta, (ii) kinematic sieving on the lee slope, (iii) grainflows, in which protruding large grains are dragged downslope by subsequent grainflows. The result is a fining upward vertical sorting in the delta. Systematic variations in the trend depend on the delta height, the migration celerity of the delta front and the flow conditions above the delta top. The dependence on delta height and migration celerity is explained by the sorting processes in the grainflows, and the dependence on flow conditions above the delta top is explained by suspension of fine sediment and settling on the lee side and toe of the delta. Large differences in sorting trends were found between various sediment mixtures. The relevance of these results with respect to sorting in dunes and bars in rivers and laboratory flumes is discussed and the elements for a future vertical sorting model are suggested.
\end{abstract}

Keywords Delta, dune, fining upward, grainflow, kinematic sieving, vertical sorting.

\section{INTRODUCTION}

\section{Scope and objective}

The downstream propagation of subaerial and subaqueous bedforms with a downstream slip face at the angle of repose such as dunes, bars and (small) Gilbert-type deltas proceeds by deposition of transported sediment on the upper part of the lee slope (grain fall), until a threshold is exceeded and the sediment mass flows downslope (grainflow). Grainflows refer to discontinuous mass flows in which the individual moving grains collide and interact. Grain fall on the other hand refers to the continuous settling of single grains from the decelerating flow just downstream of the bedform top, in which grain-grain interaction is much less important. The repeated grainflows (Allen, 1965, 1970) cause these types of bedforms to migrate downstream (Mohrig \& Smith, 1996) (Fig. 1A). In the case of higher suspension rates, the bedforms migrate partly due to suspended sediment settling on the entire lee slope, and the grain fall sediment may partly be preserved rather than be reworked in the following grainflow (Jopling, 1965; Hunter, 1985a,b) (Fig. 1B). Herein the focus is on grainflow-dominated conditions, although the two conditions cannot entirely be isolated.

In mixtures of sand and gravel, vertical grainsize sorting occurs due to grainflows, usually yielding a fining upward trend within the dune, bar or delta deposit. The vertical sorting may be modified by the grain fall sediment, which promotes coarsening upward sorting. This process is well-known and has often been observed in experiments and in the field (e.g. Allen, 1965, 1984; Brush, 1965; Termes, 1986; Love et al., 1987; Ribberink, 1987; Pye \& Tsoar, 1990; Makse, 1997; Blom et al., 2000). However, no quantitative model has been developed that successfully predicts the vertical sorting in various conditions and for different sediment mixtures. The motivation for this research is that quantification of 

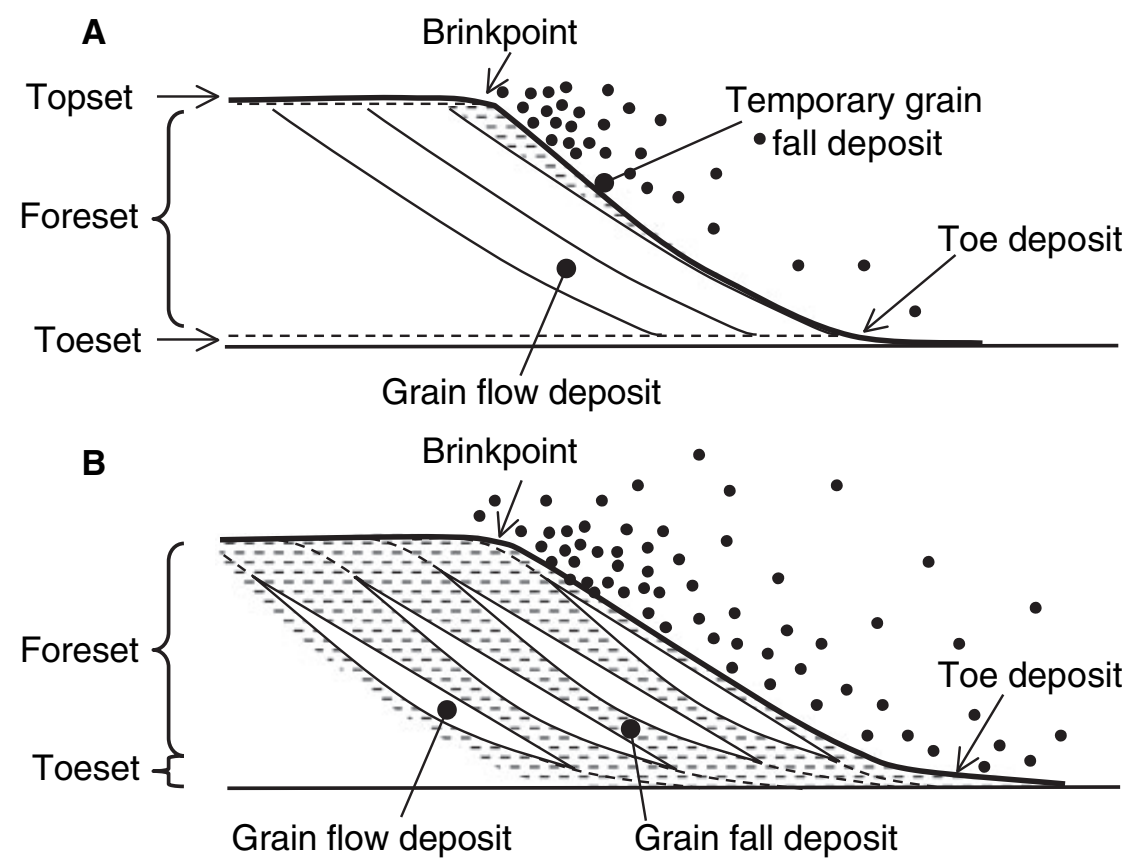

Fig. 1. (A) Sorting and definitions in sand dune deposits (after Hunter, 1985a). (B) Sorting in sand-gravel dune deposits, where only grainflow deposits are preserved on the lee slope. vertical sorting is needed for morphodynamic models for river dunes with sediment mixtures of gravel and sand (e.g. Ribberink, 1987; Parker et al., 2000). Commonly these rivers are bedloaddominated systems as the gravel rarely is suspended in natural rivers. Although the process of vertical sorting in dune beds is well known, systematic experiments in which this has been measured, are scarce. Hence, the principal variables which govern the sorting have never unequivocally been determined from systematic measurements in nature or in the laboratory. The objectives of this paper are:

1. to quantify vertical sorting,

2. to describe the sorting processes in detail, and

3. to quantify the effects of the variables that control sorting.

This is done experimentally for a range of flow conditions, sediment transport and for various mixtures.

\section{Review}

For an extensive review on vertical sorting by grainflow and grain fall the reader is referred to Kleinhans $(2002,2004)$. Sediment arriving at the brinkpoint is deposited on the upper foreset slope (Fig. 1A). In fact, grain fall occurs over a very limited downstream distance (Allen, 1965). Large grains in traction are deposited immediately downstream of the brinkpoint, while smaller grains may saltate or even be suspended and therefore take more time to settle and are deposited lower on the foreset slope. Thus the concentration, settling velocity (grain size) and accumulation of sediment decreases in the downstream direction from the top of the dune, bar or delta (Jopling, 1965). A wedge of sediment builds up on the top of the foreset, with a much faster build-up rate and coarser sediment at the top of the foreset than further downstream of the brinkpoint. This sediment wedge fails above a certain threshold and then transforms into a grainflow. The threshold is usually specified as a critical slope: the static angle of repose. When the grainflow stops moving, the sediment is deposited at the dynamic angle of repose, which usually is a few degrees smaller than the static angle of repose (Allen, 1970). During the movement of the sediment mass, kinetic sieving takes place: the small grains work down into the grainflow by occupying the small pores, with the result that the large grains are worked upwards (Brush, 1965; Makse, 1997). Consequently, the large grains on top of the lee slope may roll downslope more easily than the small grains below the large ones. In addition, the fine sediment below the large grains may provide a smoother slope for the latter, leading to an effectively smaller angle of repose of large grains on small grains than vice versa (Julien et al., 1993; Makse, 1997; Koeppe et al., 1998). 
The effects of these processes on the vertical sorting have not been studied quantitatively. The qualitative effects reviewed by Kleinhans (2004) will be summarized below and form the basis of a dimensional analysis in the next section. Factors affecting vertical sorting are:

1. The characteristics of the sediment mixture that is delivered to the top of the lee slope. Most importantly, the larger the mixture standard deviation, the more there is to sort. This may seem self-evident but there are important secondary effects of mixture characteristics. Kinetic sieving is only effective if the grain-size differences are large enough, e.g. more than about two in a bimodal mixture (Makse, 1997). Moreover, the exact shape (unimodal, skewed, bimodal) of the grain-size distribution affects the kinetic sieving and percolation, and the effective angle of repose for larger grains on top of smaller. Angular sediment has a larger angle of repose, and consequently angular particles may deposit in a higher position along the lee slope than rounded particles of the same average grain size (Makse, 1997; Koeppe et al., 1998). In the case of a mixture with rounded small grains and angular large grains, this would decrease the vertical sorting. Grain density differences will also have an effect (Julien et al., 1993) but this is neglected here because the sediments commonly found in rivers and used in the present experiments all have approximately the same density.

2. The velocity of the flow above the delta, bar or dune top relative to the settling velocities of all grain-size fractions in the mixture (Jopling, 1965). This affects the trajectory lengths of suspended grains, and therefore the length of the wedge and the importance of grain fall on the lower lee slope and toe (Allen, 1970). Given a constant static angle of repose for a certain mixture, a longer wedge will contain more sediment. Consequently the volume involved in the grainflow will be larger (Hunter \& Kocurek, 1986) and the layering in the cross-stratification will be thicker. In turn, the effectiveness of kinetic sieving decreases.

3. The frequency of the grainflows, determined by the migration celerity of the lee slope, which is in turn determined by the sediment transport rate and the height of the lee slope (Allen, 1965, 1970; Hunter \& Kocurek, 1986). When the grainflows are fast enough to overtake the previous, still active, grainflows, the thickness of the flowing sediment becomes larger and the effectiveness of kinetic sieving decreases. For higher lee slopes, the grainflow will be relatively thinner and kinetic sieving again more effective.
Allen (1970) found that for continuous grainflows and high suspension rates, the fining upward disappears or grades into coarsening upward sorting, but this was for rather well sorted sand.

4. The sediment on the lee slope beneath the grain flow may be deformed (Tischer et al., 2001) and even be mobilized (Kleinhans, 2004). Large immobile grains may be pushed down by the front of the grainflow. Due to the kinetic sieving, the lee slope is covered with relatively coarse sediment lying on relatively fine sediment, so the coarse sediment is relatively easily dragged down by the grainflow that runs over it. Since preferentially the coarse sediment on the lee slope is worked down, this process might lead to better sorting. The occurrence of this hypothetical remobilization mechanism depends on the thickness of the grainflows and the sediment mixture characteristics.

\section{THEORY}

\section{Non-dimensional description of sediment mixtures, coordinates and vertical sorting}

The sediment (factor 1 of the review) is described by a grain-size distribution, which is characterized by the geometric and arithmetic mean sediment size $\left(D_{g}, \psi_{m}\right)$ and the geometric and arithmetic standard deviation $\left(\sigma_{g}, \sigma_{a}\right)$ of the mixture:

$$
\begin{aligned}
& D_{g}=2^{\psi_{m}} ; \quad \psi_{m}=\sum_{i=1}^{N} \bar{\psi}_{i} p_{i} \\
& \sigma_{g}=2^{\sigma_{a}} ; \quad \sigma_{a}^{2}=\sum_{i=1}^{N}\left(\psi_{i}-\psi_{m}\right)^{2} p_{i}
\end{aligned}
$$

in which $\psi_{m}=$ arithmetic mean size [related to the sedimentological grain-size scale $(\phi)$ as $\psi=-\phi], \quad \psi_{i}=$ midpoint of a size fraction, $p_{i}=$ proportion in size fraction $i, \sigma_{g}=$ geometric standard deviation, and $\sigma_{a}=$ arithmetic standard deviation. The angularity and bimodality of the sediment is presently only described qualitatively.

In order to compare bedforms with different heights, the height $z$ at which a sample was taken is made dimensionless as $z^{*}=z / \Delta(\Delta=$ bedform height). The arithmetic mean size $\left(\psi_{m, z}\right)$ and arithmetic standard deviation $\left(\sigma_{a, z}\right)$ of the samples at height $z$ are made dimensionless as $\psi^{*}=\psi_{m, z}-\psi_{m, T}$ and $\sigma^{*}=\sigma_{a, z} / \sigma_{a, T}$, in which the $\psi_{m, T}$ and $\sigma_{a, T}$ describe only the sediment 
passing the brinkpoint and participating in the grain flowing process at the sampling location. The reason for this choice of the sediment will be explained in the materials and methods section. Note that $\psi^{*}$ must be made dimensionless by subtraction rather than division for the following reason. Since $D_{g}=2^{\psi}$, with $D_{g}=$ geometric mean size, it follows that:

$$
D^{*}=2^{\psi^{*}}=2^{\psi_{m, z}-\psi_{m, T}} \Rightarrow D^{*}=\frac{2^{\psi_{m, z}}}{2^{\psi_{m, T}}} \Rightarrow D^{*}=\frac{D_{g, z}}{D_{g, T}}
$$

So, the dimensionless arithmetic mean size $\left(\psi^{*}\right)$ is related to the dimensionless geometric mean size $\left(D^{*}\right)$ by $D^{*}=2^{\psi^{*}}$.

To assess the effect of certain variables on the vertical sorting, the fining upward trend along the foreset is expressed as the sorting slope of the relative grain size $\psi^{*}$ versus the depth $\left(1-z^{*}\right)$ in the bedform (not the height $z^{*}$, because the sorting slope is conveniently defined as positive for fining upward sorting with $1-z^{*}$ ). The sorting slope:

$$
\mathrm{SS}^{*}=\frac{1}{\sigma_{a, T}} \frac{\mathrm{d} \psi^{*}}{\mathrm{~d}\left(1-z^{*}\right)}
$$

is calculated for all sampled layers except the bottom and the top, to exclude the effects of the toeset on the sorting. By parametrizing the sorting with this slope, a linear relation between $\psi^{*}$ and height is assumed.

For the benefit of modelling the sorting for the full grain-size distribution rather than the $D_{g}$, this analysis is extended by considering the distribution of each grain-size fraction. Again, the distribution in $z$ of each fraction $p_{i, z}$ depends in the first place on its abundance in the mixture going over the top; $p_{i, T}$. Therefore $p_{i, z}$ is made dimensionless as $p_{i, z} / p_{i, T}$. The grain size of the fraction is made relative to the average sediment going over the top as $\psi_{i}^{*}=\psi_{m, i, z}-\psi_{m, T}$. The sorting slope for fractions $\mathrm{SF}_{i}{ }^{*}$ can be now computed for each fraction:

$$
\mathrm{SF}_{i}^{*}=\frac{\mathrm{d}\left(p_{i, z}^{*} / p_{i, T}\right)}{\mathrm{d}\left(1-z^{*}\right)}
$$

\section{Dimensional analysis}

Vertical sorting itself and the representation of the grain-size distribution (factor 1 and possibly 4 in the review) have been discussed in the previous section. The sorting slope characterizes the fining upward trend along the foresets. The dilation angle is the static angle minus the dynamic angle of repose. The measurement error of the rather small dilation angle is, however, rather large and will not be used. The suspended sediment settling velocity is $w_{s}$, and the flow conditions above the top of the slope are conveniently characterized by the depth-averaged flow velocity $(u)$ (factor 2). In factor 3 are the bedform height $(\Delta)$ and celerity $(C)$, given by $c=\left[\left(1-\lambda_{p}\right) q_{b}\right] / \Delta$, in which $q_{b}$ is the volumetric transport rate and $\lambda_{p}$ the porosity. An additional variable is the submerged specific weight of the sediment: $R g$, with $R=\left(\rho_{s}-\rho\right) / \rho$ (with $\rho=$ density of water and $\rho_{s}=$ density of sediment) and $g=$ gravitational acceleration. The thickness $h_{g}$ of each immobilized grainflow is given by $h_{g}=\sin (\theta) L / n$, with $\theta$ the dynamic angle of repose, $L$ the total progradation or migration length of the bedform and $n$ the number of grainflows. The frequency $(f)$ of grainflows was determined as $1 / T_{f}$, where $T_{f}$ is the average time between each grain flow onset. These variables can be grouped into various alternative nondimensional numbers, of which the explanatory capacity for vertical sorting will be tested on the data.

The transport rate is made dimensionless with the height:

$$
\operatorname{Tr}^{*}=\frac{q_{b}\left(1-\lambda_{p}\right)}{\sqrt{R g \Delta} \Delta}=\frac{C}{\sqrt{R g \Delta}}
$$

The celerity is made dimensionless with the geometric mean sediment size to describe the progradation in terms of the size of grains deposited on the lee slope, because the individual grain flow laminae thickness and the kinetic sieving scale with this grain size:

$$
C^{*}=\frac{C}{\sqrt{R g D_{g, T}}}
$$

As detailed information on the grain flow thickness $\left(h_{g}\right)$ (after it stopped; not in dilated mobile condition) and frequency ( $f$ ) is available and are related to the celerity $C$ as $f=C / h_{g}$, a dimensionless grainflow number $A^{*}$ can be constructed that potentially relates the sorting directly to the thickness of the laminae (as an alternative to $C^{*}$ ):

$$
A^{*}=\frac{R g}{C f}=\frac{R g h_{g}}{C^{2}}
$$

The geometric mean grain size, the mixture standard deviation and the length of the lee slope ( $\Delta / \sin \theta$, in which $\theta=$ dynamic angle of repose) 
can be combined in a dimensionless sorting number. Assuming that a longer lee slope and a higher standard deviation both lead to more efficient sorting, the sorting number is:

$$
S^{*}=\frac{\sigma_{g, T}}{D_{g, T}^{2}} \frac{\Delta}{\sin \theta}
$$

The product of the standard deviation and the length of the slope are made dimensionless with the square of the geometric mean size.

The flow conditions at the top of the slope govern the toeset deposition process and the shape of the wedge. The following reasoning is based on the ideas of Jopling (1965). The settling velocity of the finer sediment (say, of grains with a diameter that is 1 standard deviation smaller than the mean: $\psi_{m, T}-\sigma_{a, T}$ ) acts in the vertical direction (downwards) while the flow velocity at the top gives the grains an initial momentum in the horizontal direction (downstream). It can now be seen that the path of the grains from the top to the toeset deposit is related to $u / w_{s}$ and to the horizontal distance between top and toe $(\Delta / \tan \theta)$. As the water depth $h_{1}$ is very small relative to the bedform height in the experiments reported here, the initial grain height above the lee slope top (Jopling, 1965) is simply assumed to be $0 \cdot 5 h_{1}$. For larger water depths, this analysis should include the flow velocity and sediment concentration of all sediment sizes in the vertical direction. The following non-dimensional grain fall number can be constructed:

$$
G^{*}=\frac{u}{W_{s}} \frac{\tan \theta\left(\frac{1}{2} h_{1}+\Delta\right)}{\Delta}
$$

\section{MATERIALS AND METHODS}

The vertical sorting as a result of grain fall is opposite to that of grainflows. Herein it was attempted to isolate the grainflow process as much as possible in order to obtain the largest possible sorting. The experiments were therefore done with a very small (Froude-critical) water depth above the bedform compared to the water depth downstream of the bedform to maximize the flow expansion and minimize the height and length of suspended grain trajectories. This was done by generating deltas rather than dunes. Deltas were created with different heights, sediment feed rates and sediments.

Two sets of experiments were done. Experimental series 1 was with a wide sand-gravel mixture (N, see Table 1 and Fig. 2) to test the effect of delta height (water depth $h_{0}$ ) and celerity (related sediment discharge and delta height as $\left.c=\left[\left(1-\lambda_{p}\right) q_{b}\right] / \Delta\right)$. These two were systematically varied in combinations of three target water

\begin{tabular}{|c|c|c|c|c|c|c|c|c|c|c|c|c|}
\hline No. & $\begin{array}{l}h_{0} \\
(\mathrm{~m})\end{array}$ & $\begin{array}{l}q \\
\left(\mathrm{~m}^{2} \mathrm{sec}^{-1}\right)\end{array}$ & $\begin{array}{l}h_{1} \\
(\mathrm{~m})\end{array}$ & $\begin{array}{l}i \\
(-)\end{array}$ & $\begin{array}{l}C \\
\left(\mathrm{~cm} \min ^{-1}\right)\end{array}$ & $\begin{array}{l}D \\
(\mathrm{~m})\end{array}$ & $\begin{array}{l}q_{b}{ }^{*} \\
\left(\mathrm{~m}^{2} \mathrm{sec}^{-1}\right)\end{array}$ & $\begin{array}{l}T_{f} \\
\text { (sec) }\end{array}$ & $\begin{array}{l}T_{g} \\
\text { (sec) }\end{array}$ & $\begin{array}{l}\theta_{\text {dilat }} \\
\left(^{\circ}\right)\end{array}$ & $\begin{array}{l}h_{g} \\
(\mathrm{~mm})\end{array}$ & $\begin{array}{l}D_{g T} \\
(\mathrm{~mm})\end{array}$ \\
\hline \multicolumn{13}{|c|}{ Experimental series 1} \\
\hline N1 & $0 \cdot 200$ & $3 \cdot 1 \mathrm{E}-04$ & $0 \cdot 008$ & $0 \cdot 063$ & $7 \cdot 92$ & $0 \cdot 18$ & $3 \cdot 9 \mathrm{E}-04$ & $9 \cdot 41$ & $3 \cdot 77$ & $4 \cdot 8$ & $6 \cdot 50$ & $1 \cdot 56$ \\
\hline N2 & $0 \cdot 203$ & $2 \cdot 9 \mathrm{E}-04$ & $0 \cdot 010$ & $0 \cdot 032$ & $2 \cdot 40$ & $0 \cdot 19$ & $1 \cdot 3 \mathrm{E}-04$ & $20 \cdot 65$ & $3 \cdot 48$ & $4 \cdot 8$ & $8 \cdot 59$ & $1 \cdot 33$ \\
\hline N3 & $0 \cdot 200$ & $4 \cdot 2 \mathrm{E}-04$ & $0 \cdot 010$ & $0 \cdot 066$ & $10 \cdot 71$ & $0 \cdot 18$ & $5 \cdot 4 \mathrm{E}-04$ & $7 \cdot 71$ & $3 \cdot 49$ & $6 \cdot 3$ & $7 \cdot 11$ & $1 \cdot 45$ \\
\hline $\mathrm{N} 4$ & $0 \cdot 300$ & $4 \cdot 5 \mathrm{E}-04$ & $0 \cdot 010$ & $0 \cdot 067$ & $7 \cdot 50$ & $0 \cdot 28$ & $6 \cdot 8 \mathrm{E}-04$ & - & - & $3 \cdot 3$ & - & $1 \cdot 44$ \\
\hline N5 & $0 \cdot 301$ & $4 \cdot 2 \mathrm{E}-04$ & $0 \cdot 010$ & $0 \cdot 067$ & $4 \cdot 79$ & $0 \cdot 28$ & $4 \cdot 5 \mathrm{E}-04$ & $14 \cdot 67$ & $5 \cdot 16$ & $5 \cdot 3$ & $6 \cdot 17$ & $1 \cdot 41$ \\
\hline N6 & $0 \cdot 299$ & $3 \cdot 7 \mathrm{E}-04$ & $0 \cdot 010$ & 0.037 & $2 \cdot 48$ & $0 \cdot 28$ & $2 \cdot 3 \mathrm{E}-04$ & $21 \cdot 81$ & $5 \cdot 56$ & $5 \cdot 0$ & $5 \cdot 68$ & $1 \cdot 34$ \\
\hline N7 & $0 \cdot 080$ & $3 \cdot 5 \mathrm{E}-04$ & $0 \cdot 011$ & 0.036 & $8 \cdot 43$ & $0 \cdot 07$ & 1·3E-04 & $4 \cdot 97$ & 1.94 & $4 \cdot 0$ & $3 \cdot 56$ & $1 \cdot 33$ \\
\hline N8 & $0 \cdot 081$ & $3 \cdot 3 \mathrm{E}-04$ & $0 \cdot 012$ & 0.026 & $3 \cdot 69$ & $0 \cdot 07$ & $5 \cdot 6 \mathrm{E}-05$ & $7 \cdot 66$ & $1 \cdot 89$ & $4 \cdot 8$ & $2 \cdot 47$ & $1 \cdot 23$ \\
\hline N9 & $0 \cdot 082$ & $3 \cdot 9 \mathrm{E}-04$ & $0 \cdot 011$ & 0.014 & $5 \cdot 27$ & $0 \cdot 07$ & $7 \cdot 7 \mathrm{E}-05$ & $7 \cdot 21$ & $1 \cdot 83$ & $4 \cdot 8$ & $3 \cdot 32$ & $1 \cdot 22$ \\
\hline N10 & $0 \cdot 080$ & $5 \cdot 2 \mathrm{E}-04$ & $0 \cdot 013$ & 0.039 & $34 \cdot 50$ & $0 \cdot 06$ & $4 \cdot 3 \mathrm{E}-04$ & $3 \cdot 00$ & $1 \cdot 76$ & $4 \cdot 8$ & $8 \cdot 63$ & $1 \cdot 47$ \\
\hline N11 & $0 \cdot 198$ & $3 \cdot 9 \mathrm{E}-04$ & $0 \cdot 011$ & $0 \cdot 034$ & $3 \cdot 53$ & $0 \cdot 18$ & $1 \cdot 8 \mathrm{E}-04$ & $14 \cdot 67$ & $5 \cdot 02$ & $4 \cdot 8$ & $6 \cdot 11$ & $1 \cdot 33$ \\
\hline \multicolumn{13}{|c|}{ Experimental series 2} \\
\hline M1 & $0 \cdot 200$ & $4 \cdot 4 \mathrm{E}-04$ & $0 \cdot 010$ & $0 \cdot 069$ & $9 \cdot 60$ & $0 \cdot 19$ & $5 \cdot 7 \mathrm{E}-04$ & $9 \cdot 92$ & $3 \cdot 56$ & $5 \cdot 0$ & $9 \cdot 26$ & $3 \cdot 71$ \\
\hline U1 & $0 \cdot 201$ & $4 \cdot 2 \mathrm{E}-04$ & $0 \cdot 010$ & $0 \cdot 069$ & $9 \cdot 09$ & $0 \cdot 19$ & $5 \cdot 1 \mathrm{E}-04$ & $9 \cdot 49$ & $3 \cdot 08$ & $5 \cdot 0$ & $7 \cdot 95$ & $2 \cdot 49$ \\
\hline S1 & $0 \cdot 200$ & $4 \cdot 2 \mathrm{E}-04$ & $0 \cdot 012$ & $0 \cdot 027$ & $3 \cdot 62$ & $0 \cdot 18$ & 1.9E-04 & $19 \cdot 15$ & $7 \cdot 07$ & $2 \cdot 0$ & $6 \cdot 18$ & $0 \cdot 30$ \\
\hline $\mathrm{S} 2$ & $0 \cdot 080$ & $4 \cdot 1 \mathrm{E}-04$ & $0 \cdot 010$ & $0 \cdot 036$ & $26 \cdot 67$ & $0 \cdot 07$ & $3 \cdot 6 \mathrm{E}-04$ & $3 \cdot 05$ & $1 \cdot 52$ & $2 \cdot 0$ & $7 \cdot 15$ & $0 \cdot 77$ \\
\hline A1 & $0 \cdot 200$ & $3 \cdot 4 \mathrm{E}-04$ & $0 \cdot 010$ & $0 \cdot 060$ & $6 \cdot 83$ & $0 \cdot 19$ & $4 \cdot 3 \mathrm{E}-04$ & $12 \cdot 84$ & $2 \cdot 95$ & $8 \cdot 3$ & $7 \cdot 68$ & 0.88 \\
\hline C1 & $0 \cdot 205$ & $3 \cdot 9 \mathrm{E}-04$ & $0 \cdot 010$ & $0 \cdot 086$ & $12 \cdot 00$ & $0 \cdot 19$ & $7 \cdot 1 \mathrm{E}-04$ & $8 \cdot 53$ & $3 \cdot 05$ & $5 \cdot 0$ & $8 \cdot 96$ & $1 \cdot 01$ \\
\hline $\mathrm{C} 2$ & $0 \cdot 208$ & $5 \cdot 8 \mathrm{E}-04$ & $0 \cdot 012$ & 0.072 & $13 \cdot 47$ & $0 \cdot 19$ & $7 \cdot 8 \mathrm{E}-04$ & $7 \cdot 20$ & $2 \cdot 88$ & $5 \cdot 0$ & $7 \cdot 96$ & $3 \cdot 59$ \\
\hline
\end{tabular}

Table 1. Basic data of the experiments.

*The volumetric bedload transport rate $\left(q_{b}\right)$ includes the pore space. 

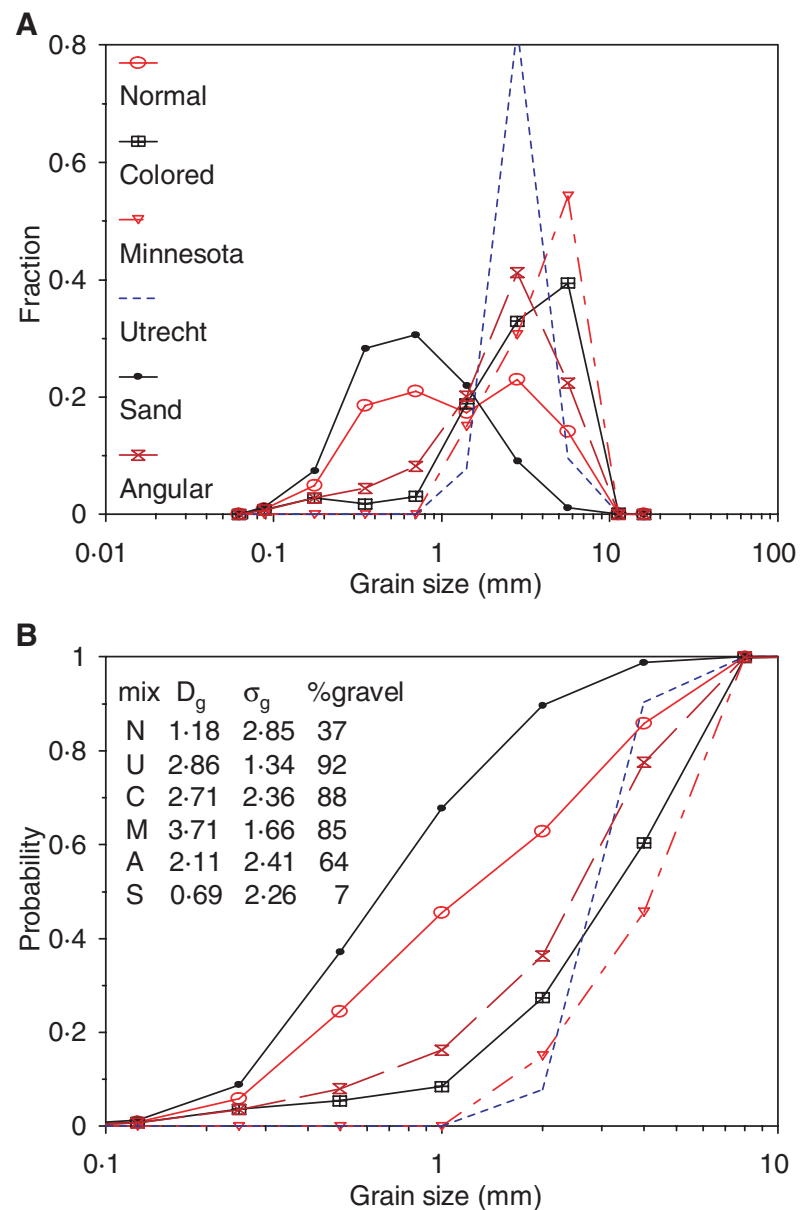

Fig. 2. Grain-size distributions of the sediment mixtures fed into the flume in non-cumulative (A) and cumulative (B) sieve curves. $D_{g}=$ geometric mean size $(\mathrm{mm}), \sigma_{g}=$ geometric standard deviation. All sediments had a density of approximately $2650 \mathrm{~kg} \mathrm{~m}^{-3}$ and a porosity varying between $0 \cdot 30$ and $0 \cdot 36$. The $U$ and $M$ mixtures are subsets (two colour-coded fractions) of the $\mathrm{C}$ mixture, the $\mathrm{S}$ is a subset of $\mathrm{N}$ after removal of most of the pea gravel in $\mathrm{N}$, and $\mathrm{A}$ is crushed granite of which the fractions $>1 \mathrm{~mm}$ is highly angular and $<1 \mathrm{~mm}$ is as angular as in the $\mathrm{N}$ and $\mathrm{S}$ mixtures.

depths $(0.08,0.2$ and $0.28 \mathrm{~m})$ and three target celerities $\left(3,6\right.$ and $\left.9 \mathrm{~cm} \mathrm{~min}^{-1}\right)$. Due to the limitations of the sediment feeder, higher celerities were only applied with smaller deltas (experiment $\mathrm{N} 3$ and N10).

Experimental series 2 was done with a variety of sediment mixtures that were available, to study the effect of sediment size, angularity and mixture bimodality (or skewness depending on how the fine tail is described) (Table 1 and Fig. 2). The coloured sediment was convenient because the grain-size fractions were colourcoded, and consisted mostly of rounded gravel and of a tail of fine (white) sand. The Minnesota and Utrecht mixtures are subsets of the coloured sediment to obtain narrower mixtures. The sand mixture is a subset of the normal mixture from which most of the pea-gravel had been removed. The angular mixture is crushed granite and therefore angular compared to the other mixtures which had rounded grains. This applies mostly to the coarser grains in the mixture as the sand grains in $\mathrm{A}$ are as angular in those of the $\mathrm{S}$ and $\mathrm{N}$ mixtures.

The experiments of the second set were all done with the intermediate delta height of $0.2 \mathrm{~m}$, except one where the aim was again to obtain a very high celerity. The latter experiment (S2) tested whether the condition of much suspension and continuous grainflows leads to absence of vertical sorting (see Allen, 1970). There are two experiments with the bimodal $\mathrm{C}$ mixture of which the flow discharge in $\mathrm{C} 2$ is 1.5 times larger than in C1. This experiment was done to test the effect of higher flow velocity over the delta top on the suspension and trajectory of the fine sand tail of the $\mathrm{C}$ mixture. The $\mathrm{S} 2$ and $\mathrm{C} 2$ experiments can be seen as exploratory and preliminary.

The experiments were done in a narrowed flume at St Anthony Falls Laboratory (Fig. 3), which had a length of $7 \mathrm{~m}$, a depth of $0.38 \mathrm{~m}$ and a width of $0.075 \mathrm{~m}$. Water and sediment were fed at a constant and adjustable rate at the upstream end of the flume. The water depth in the basin $\left(h_{0}\right)$ was fixed with the downstream weir. The flow on the delta developed to its own equilibrium slope $(i)$ and water depth $\left(h_{1}\right)$ for the given discharge and sediment load. The water depth $h_{1}$ was measured through the glass wall and in the middle of the flume, while the bed slope was measured at the end of the experiments from bed level measurement at every $0.1 \mathrm{~m}$ along the delta at both sidewalls. The flow discharge $(Q)$ was determined twice per run by measuring the time it took to fill a bucket of known volume. The flow velocity $(u)$ over the delta was determined from water depth $\left(h_{1}\right)$, flow discharge and flume width $(W)$ from $u=Q /\left(W h_{1}\right)$. The slope (i) was determined from the bed elevation along the alluvial topset of the deltas. From the slope and the water depth $\left(h_{1}\right)$ the total shear stress $(\tau)$ was determined with $\tau=\rho g h_{1} i$. The dimensionless (Shields) shear stress is computed as $\tau^{*}=\tau / \rho D_{g}$. The width/depth ratio was about 8 so a sidewall roughness correction was unnecessary. The determination of the water depth through the glass wall, however, is inaccurate: $\pm 1 \mathrm{~mm}$ which corresponds for most experiments to $\pm 10 \%$. The water temperature was $10^{\circ} \pm 1^{\circ} \mathrm{C}$. 


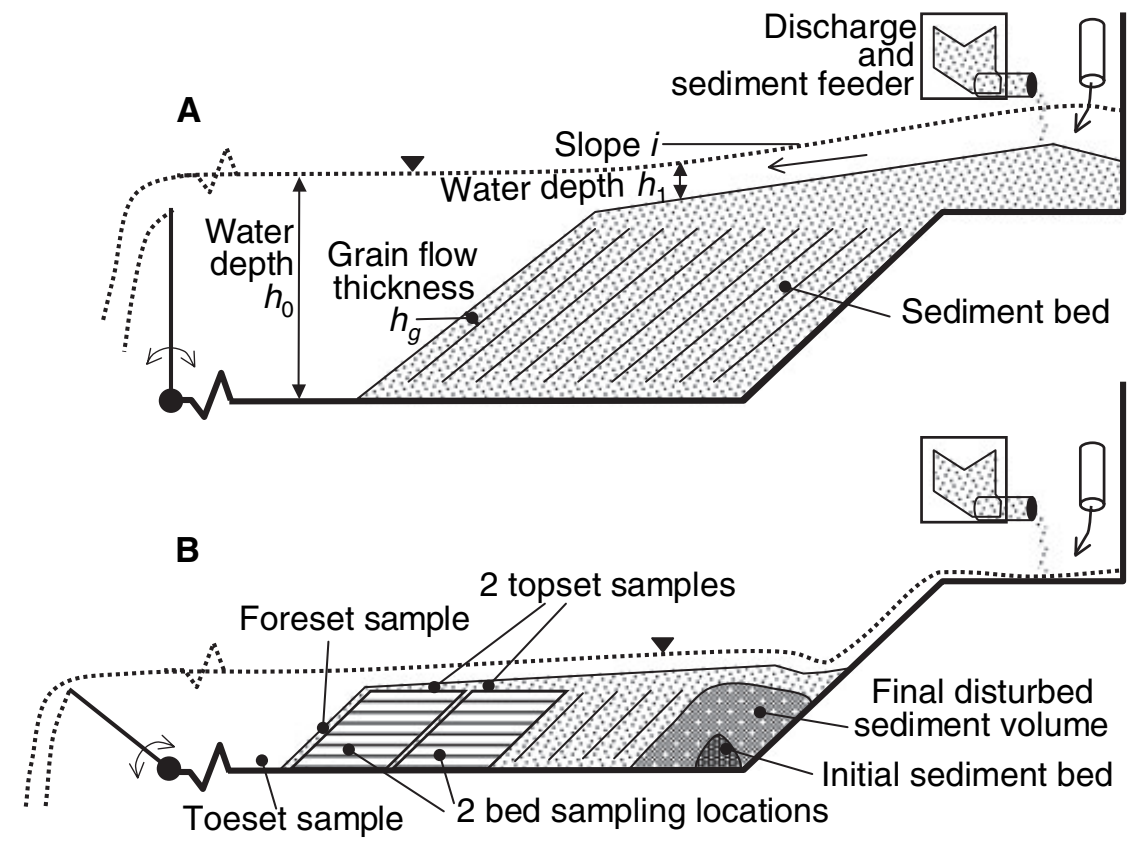

Fig. 3. Outline of the Delta Flume at St Anthony Falls Laboratory (vertical scale exaggerated and length cut off in the drawing near the weir). (A) Case with $0 \cdot 3 \mathrm{~m}$ high deltas showing the hydraulic parameters. (B) Case with $0.08 \mathrm{~m}$ high deltas showing the initial disturbed sediment and the sediment sampling locations.

Grain flow thickness, duration and frequency were determined from analysing the timing of onset and stopping of grain flows from close-up digital videos, excluding the initial $0.15 \mathrm{~m}$ of accreted sediment. The duration $T_{g}$ of grainflows was determined as $T_{g}=t_{\text {immobilizing }}-t_{\text {onset }}$ from the time base of the videos. During each run, the angle of the prograding deltafront was measured manually just before and after the individual grain flow events, to determine the static and dynamic angles of repose.

After the water was drained from the flume, the bed was photographed from both sidewalls and from the top of the flume. The bed surface elevation was measured for the determination of the slope and the total volume of sediment. At two horizontal positions in the delta (at the downstream end and just upstream, Fig. 3B), the bed was sampled vertically in horizontal layers of $1.5-2 \mathrm{~cm}$ thickness over a length of 15-20 cm for grain size analysis by dry sieving (comparable to collecting a core and slicing the core in thin layers). The topset, the toeset (over a length of $0.2 \mathrm{~m}$ immediately downstream of the delta slipface) and the foreset (1-2 grains thick, between topset and toeset) were sampled separately. The first 0.1-0.15 $\mathrm{m}$ of the delta was not sampled as it represented the initial accumulation phase, while beyond $0.15 \mathrm{~m}$ a simple Gilbert-type delta progressively developed down the flume.

In order to maintain a constant bed slope, some sediment is deposited in the topset while the brinkpoint of the delta migrates downstream. The sediment in the topset is slightly downstream fining for $i<0.05$ and downstream coarsening for $i>0.05$. Thus, the feeder sediment is not exactly the same as the sediment going over the brinkpoint to participate in the grain flows because of size-selective sediment transport and deposition in the upstream topset. Therefore the samples at all heights $z$ at each sampling location in the deltas, was averaged over the depth to determine the grain size distribution of the sediment participating in the grain flows. This average composition therefore excludes the topset and toeset sediment.

\section{RESULTS}

\section{Basic data}

The basic data are presented in Table 1. The main body of the delta is the fining upward deposit from the grainflows (example in Fig. 4A). On top of the delta, there is an alluvial topset at an angle equal to that of the water surface slope of the flow which transported the sediment from the inlet to the brinkpoint of the delta (Fig. 4B). This slope was straight in all cases except in the most upstream few $\mathrm{cm}$ where water and sediment entered the flume. In most experiments a toeset formed by settling of sediment that was suspended at the brinkpoint. When this sediment was overrun by the prograding delta, it became a bottomset. 

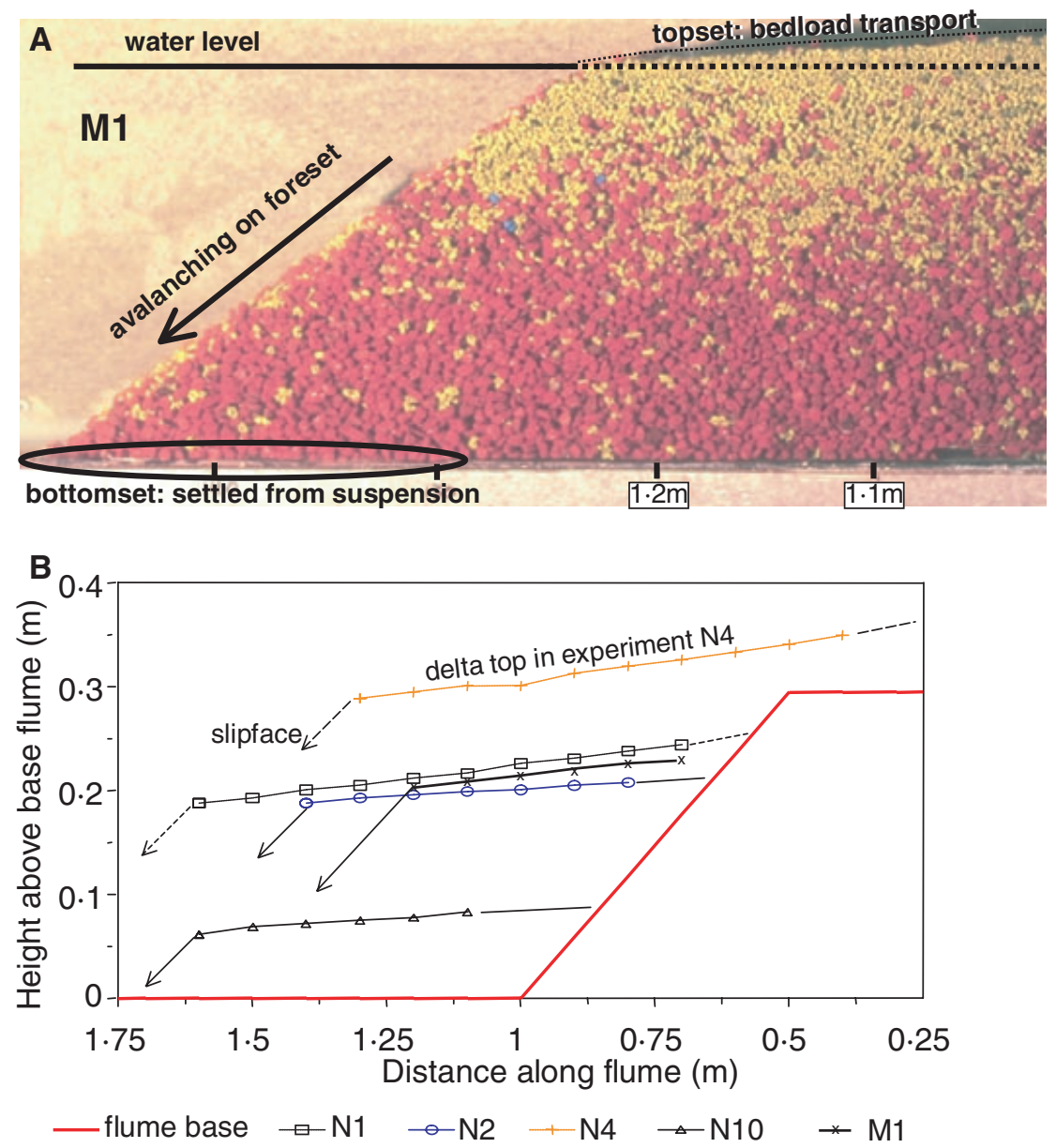

Fig. 4. (A) Fining upward sorting in delta M1. The dark grains are large, the light grains are small. Position of bottomset in deltas with finer sediment is indicated for clarity. Scale (in $\mathrm{m}$ ) at the bottom of the photograph is the same as in (B). (B) Examples of surface profiles of some experiments, which were used to determine the alluvial slope and the total volume of the delta (for determination of sediment transport).

\section{Process description of sorting in the grainflow}

The following qualitative description is based on visual observations done during the experiments and verified with the videos (Fig. 5). The sorting in the grainflows in the $\mathrm{N}$ experiments is a threestage process. The first process is the deposition of sediment from grain fall just downstream of the delta top. The flow carries the sediment downstream from the delta top, and meanwhile the grains settle to the slip face. Thus a wedge-shaped mass of mixed sediment is built up at the upper few $\mathrm{cm}$ of the lee slope from the sediment 'raining' from suspension. Beyond the zone just downstream of the delta top, however, there was very little suspended sediment, except in the N10 and S2 experiments. For the smaller grains, the trajectory is longer and the smallest grains are even deposited downstream of the delta as a thin toeset. The toesets were less than $1 \mathrm{~mm}$ thick at $0 \cdot 1 \mathrm{~m}$ downstream of the delta toes, except in N10 and S2 where it was a few mm thick. The static angle of repose of the wedge-shaped mass is larger $\left(37^{\circ}\right.$ for the $\mathrm{N}$ experiments) than the dynamic angle of repose of the lower lee slope $\left(32^{\circ}\right)$.

Second, the sediment mass moves downslope over a small distance (less than half the lee slope length). The accommodation space thus created is filled by the continuous grain fall. During the small downslope movement of the sediment, the gravel is worked upwards in the moving layer by kinetic sieving. As a consequence, the lee slope is covered with the coarsest sediment from top to toe for most of the time.

Third, at some point roughly the whole upper half of the lee slope sediment fails and moves downslope as a large grain flow, usually about $8 \mathrm{~mm}$ thick in the $\mathrm{N}$ experiments. The statistics of these large grainflows will be presented later. The gravel on the lower half of the lee slope is partly dragged along and partly pushed ahead of the flow, contributing to the upward fining. The plane at which the sediment fails is in the middle of the previous grainflow deposit between its gravelly surface and the underlying finer sediment. This underlying sediment is sandy near the delta top and gravelly near the base, and is finer 

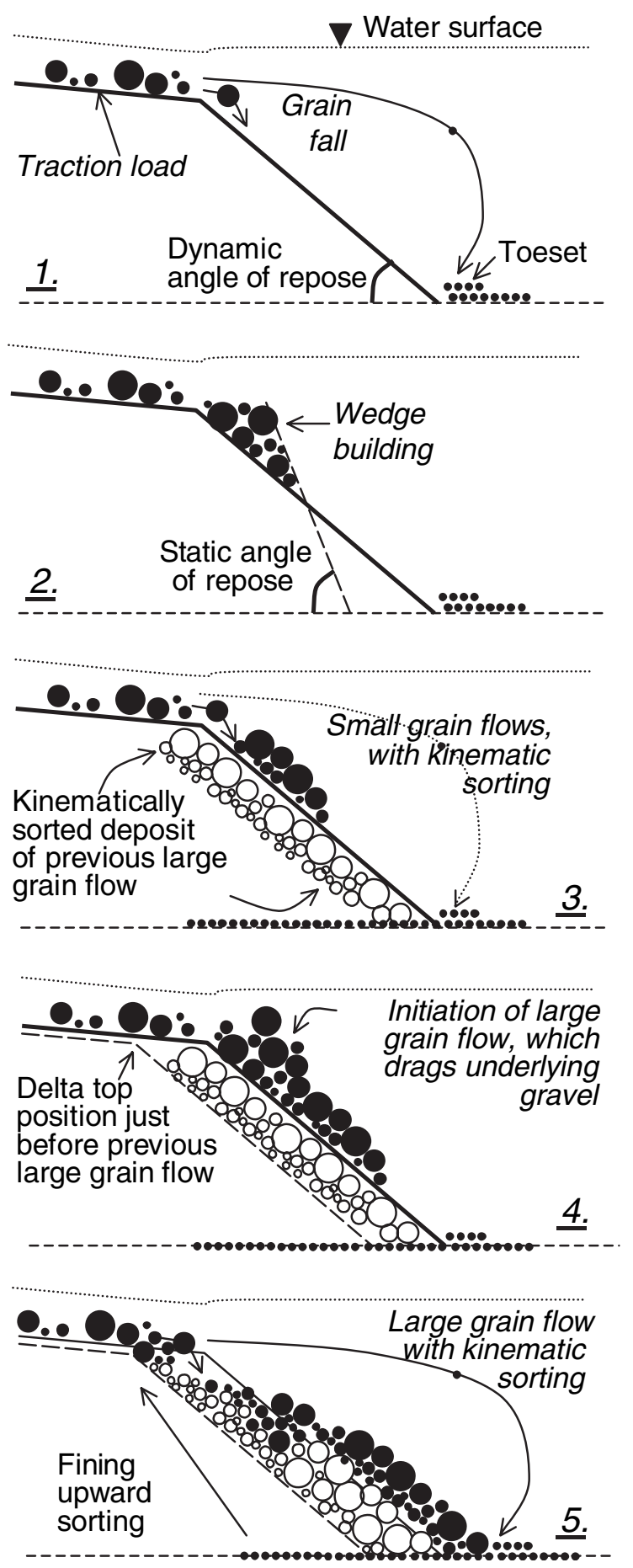

Fig. 5. Conceptual model of the sediment deposition and sorting on the lee slope of the experimental deltas. The three stages of the process are given: 1,2: grain fall creating the sediment wedge and the toeset, 3: small grainflows with kinetic sieving, and 4,5: large grainflows that drag the top of the previous grainflow deposit downslope, leading to the fining upward. The dynamic and static angle of repose, the sorted deposit of the previous large grainflow and the previous position of the delta front are introduced in the first four panels, but are present in all time steps in reality. than the lee slope surface along most of the slope. So mostly the gravelly top of the previous grainflow is both pushed and dragged downslope by the next grainflow, which contributes to the observed upward fining in the delta. As no fine sediment drapes were found on the lee slopes and no clear cross-lamination was observed, the deposited sediment from grain fall on top of the grainflows must have been incorporated into the grainflows by kinetic sieving immediately. Sometimes bedload sheets were observed on the topset (but never downstream of the brinkpoint), but the volume of sediment in these bedload sheets was much smaller than the volume of the wedge, so the grainflows were solely driven by wedge collapse.

When the grainflow reaches the bottom of the flume (top of the toeset), the gravelly head of the flowing sediment mass stops moving first and within a second or so all the sediment becomes immobilized. The surface of the stabilized grainflow is again gravelly, while the top of the delta is sandy. As the slope of the immobilized grainflow (dynamic angle of repose) is smaller than the static angle of repose, there is a new accommodation space for sediment depositing from grain fall, and the process starts anew.

\section{Overall vertical sorting}

Figures 6 and 7 show the non-dimensionalized vertical sorting data for the two experimental series. In all experiments, the sediment was sorted fining upward, and the $\sigma^{*}$ at most heights is smaller than unity because the sediment is vertically sorted and therefore had a smaller standard deviation than the total mixture going over the delta top. The notable exception is the base of most of the deltas, which has a larger $\sigma^{*}$ because the fine sediment of the toeset is mixed with the coarse sediment of the lowest part of the foresets. The deltas without fine sediment (M1 and U1) do not have this toeset.

Two examples (Fig. 8A and B) demonstrate that the fractions are distributed along the lee slope as expected in such a way that the net sorting is fining upward, but the 'structure' differs between the mixtures. The finer sediment fractions are better represented in higher positions in the delta and the coarser sediment fractions in the lower positions. The presence of the finest fraction in the lowest sampled layer was explained above (Fig. 8A and B). There is a structural difference between N6 and C1,2: in the N6 delta the coarsest fraction has a relatively higher abundance in the 

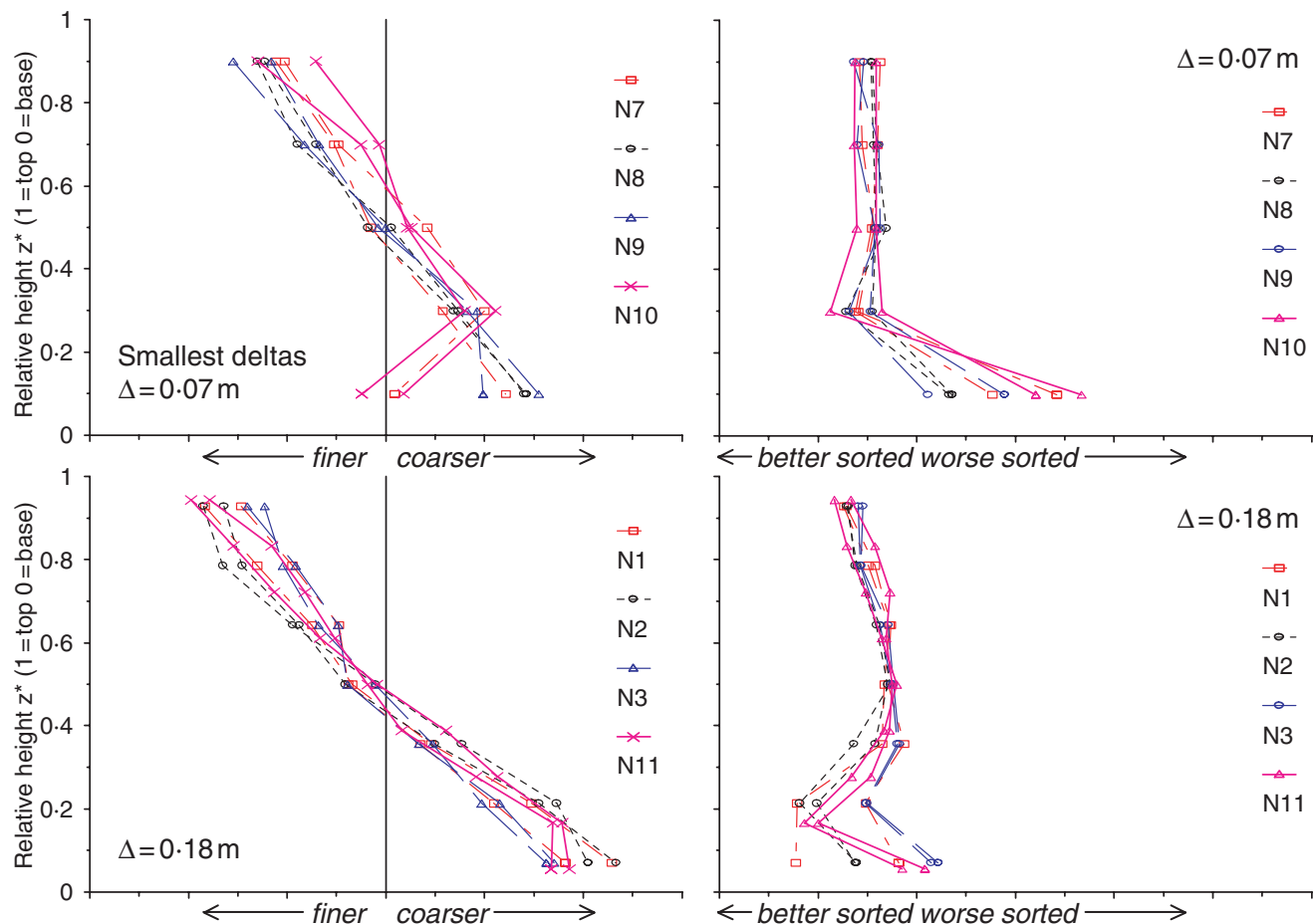

N7

$-\bullet-$

$\rightarrow$

N9

$\stackrel{\wedge}{\mathrm{N} 10}$
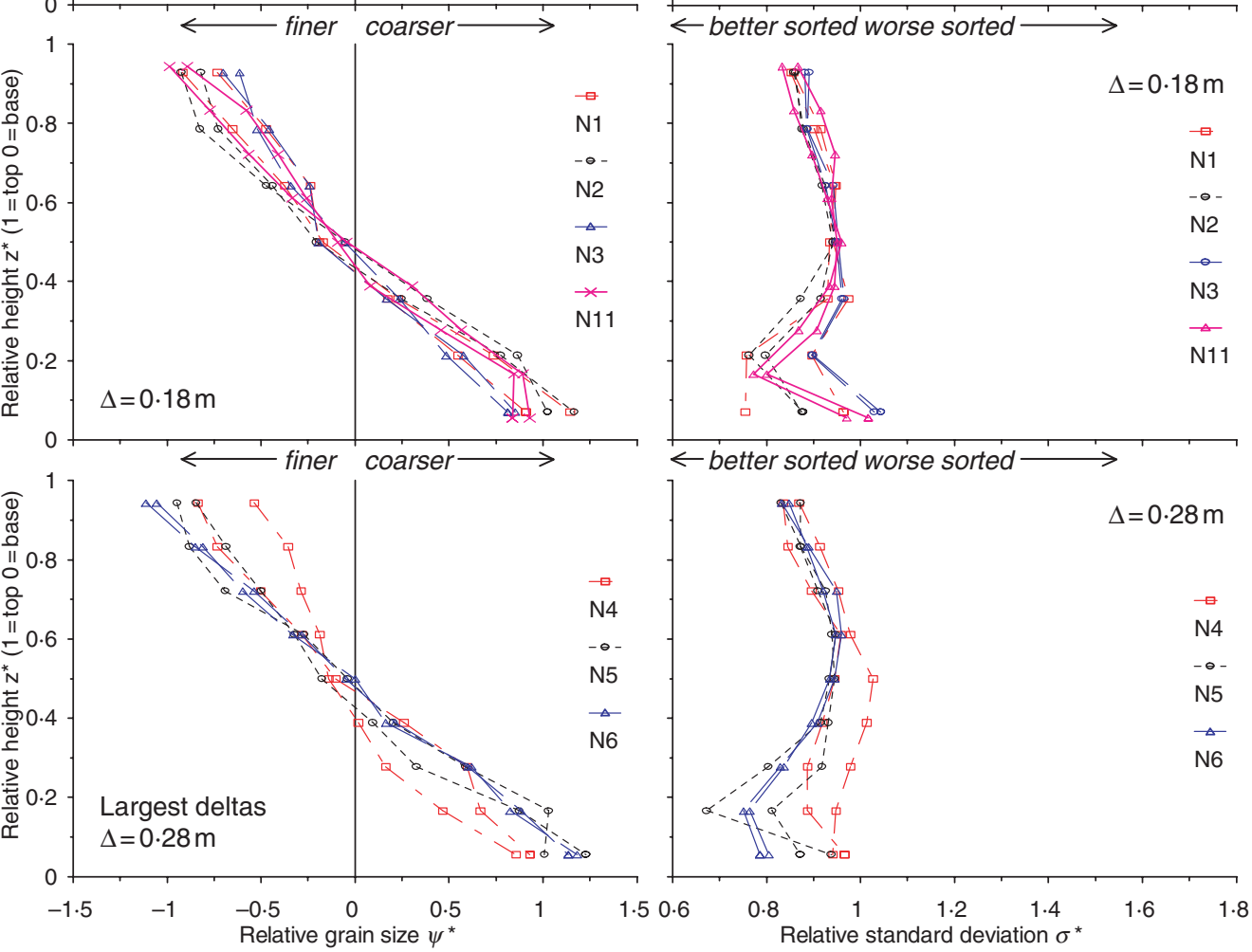

Fig. 6. The sorting in the deltas of series 1 with the $\mathrm{N}$ sediment mixture. The vertical axis is relative height $z^{*}=z / \Delta$. The horizontal axis of the left-side panels is the relative sediment size $\psi^{*}=\psi_{m, z}-\psi_{m, T}$ which is the logarithm of the ratio of the sediment diameter at a certain height $\left(D_{g, z}\right)$ and the diameter of all the sediment in the delta $\left(D_{g, T}\right)$ : $2^{\psi^{*}}=D_{g, z} / D_{g, T}$. The relative mixture standard deviation is $\sigma^{*}=\sigma_{a, z} / \sigma_{a, T}$. The topset and toe deposit have not been included. The bottomset, however, is included in the samples taken at the base of the deltas. The sorting curves have been grouped for delta height. For most $\mathrm{N}$ experiments, two curves are shown as the delta was sampled twice.

lowest layer compared to the trend in the layers above (Fig. 8A), whereas in the $\mathrm{C}$ deltas the coarsest two fractions have moderate abundances over the full depth while the finer fractions show a much more pronounced distribution pattern (Fig. 8B). This is likely to be a result of the mechanism of dragging coarse sediment downslope by the next grainflow, which is absent in C1,2 but clearly present in the $\mathrm{N}$ mixtures.

This structure in the fractionwise sorting data is visualized in a different manner in Fig. 8C and D. The N, C and A mixtures all show a 'lazy S-shaped' structure (schematized by the curves in Fig. 8C and D), in which the fine grain-size fractions are more abundant in the delta tops and coarse grain-size fractions more abundant in the lower parts of the delta. The structure of the $\mathrm{N}$ mixture is slightly modified by the delta height and delta celerity. The celerity has the strongest effect on vertical sorting for the larger deltas. The $\mathrm{U}, \mathrm{M}$ and $\mathrm{S}$ mixtures, which are relatively narrow, have different shapes (Fig. 8D) with less pronounced vertical sorting. The N, C and A mixtures, which are all relatively wide, have comparable structures. It is also clear that the assumption of a linear function in the definition of the sorting slope (Eq. 4) is violated for the grain-size fractions approach. 


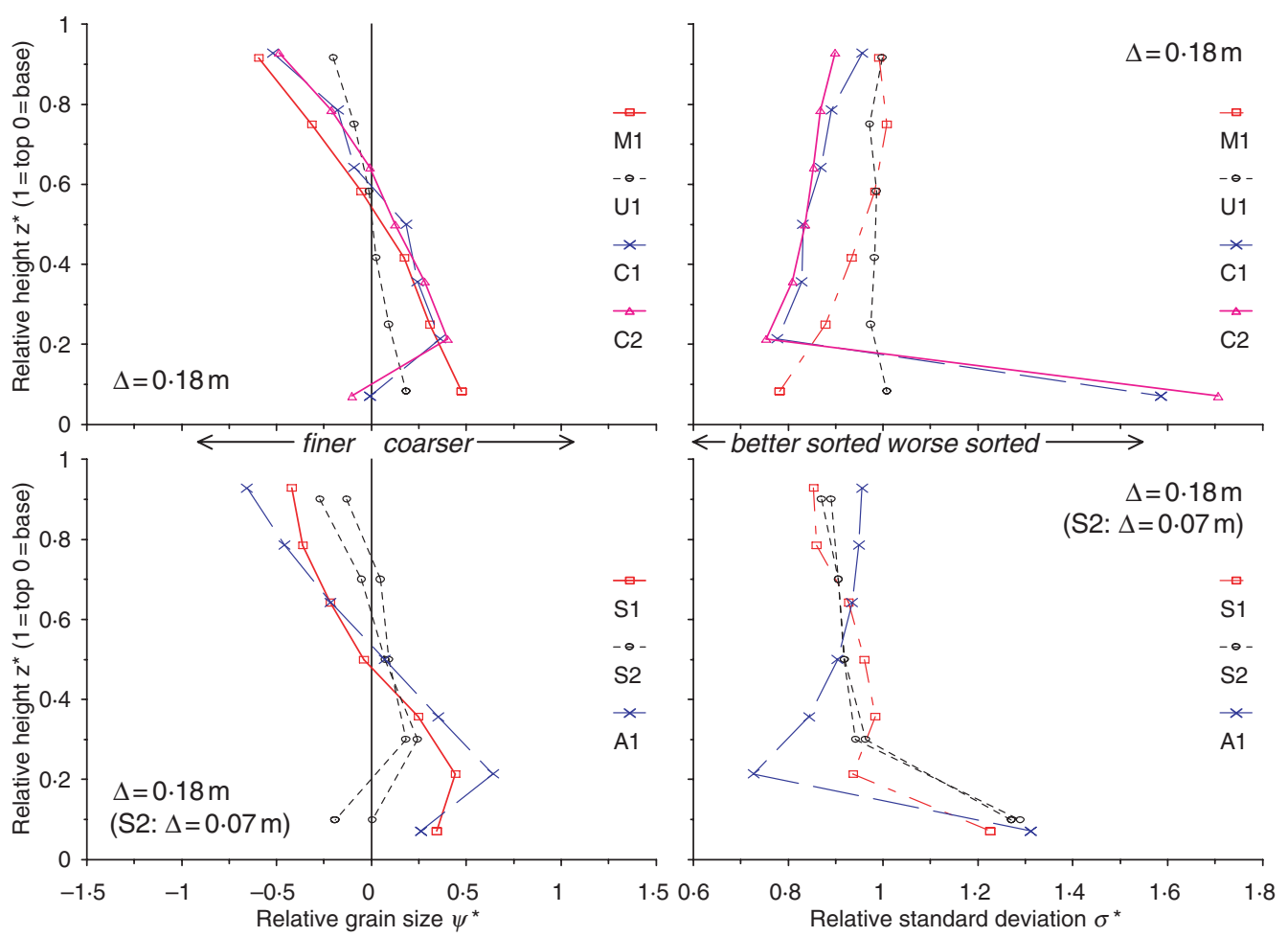

Fig. 7. Same as Fig. 6, now for the alternative sediment mixtures of experimental series 2 .
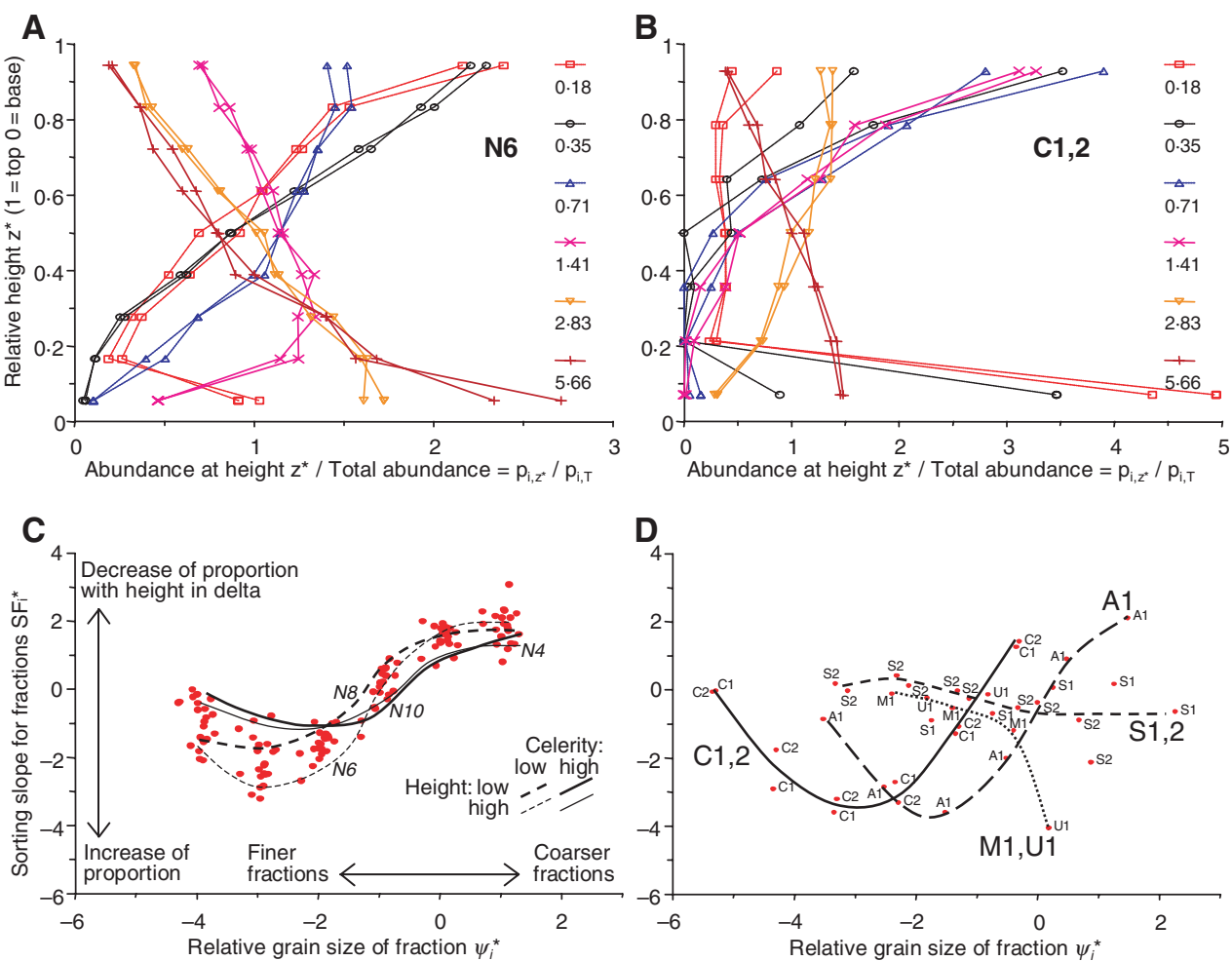

Fig. 8. Vertical sorting of grain-size fractions. (A) Data of N6 (legend indicates grain size of the fraction). (B) Data of $\mathrm{C} 1$ and C2. (C) Sorting slope of each fraction $\mathrm{SF}_{i}^{*}$ in N experiments as a function of relative grain size of the fraction $\psi_{i}^{*}$. Lines through the data were fitted by eye for selected experiments to show the differences between high and low deltas and high and low celerities. (D) As (C), for various sediments of experimental series 2. 


\section{Effect of grainflow kinematics on vertical sorting}

The probability distributions of the duration of grainflows, and interval between grainflows are shown in Fig. 9. The length and variation of the grainflow duration $\left(T_{g}\right)$ depends on the length of the lee slope: $T_{g}$ is much longer for N6 than for N8, whereas N8 and N10 have almost the same $T_{g}$ even though their $C^{*}$ is very different. The length and variation of the grainflow interval $\left(T_{f}\right)$, on the other hand, depends mostly on $C^{*}$ as the slow N6 has both larger interval and variation in that interval than N10 which is almost continuously grainflowing. These findings indicate that the grainflows are initiated by wedge failure, which depends on a fixed volume of the wedge which would cause much variation in the $T_{g}$.

\section{Dimensionless parameters affecting vertical sorting: results}

The relation between the dimensionless numbers and the vertical sorting in the foreset deposits is shown in Fig. 10. Within the given range of transports and celerities, the sorting slope ranges from 2 (the maximum) to almost zero (the minimum) with increasing $C^{*}$ and $\operatorname{Tr}^{*}$ and decreasing $S^{*}$. A significant correlation between one of these parameters and the sorting slope $\mathrm{SS}^{*}$ indicates a contribution to the description of the sorting; a significant correlation between the parameters, however, indicates redundancy of parameters. The correlations in Table 2 indicate that the $C^{*}$ and $S^{*}$ are the most relevant for vertical sorting, whereas the $\mathrm{Tr}^{*}$ and $G^{*}$ are redundant. The correlation of $A^{*}$ with $\mathrm{SS}^{*}$ is higher than that between $C^{*}$ and $\mathrm{SS}^{*}$, but data for $A^{*}$ are difficult
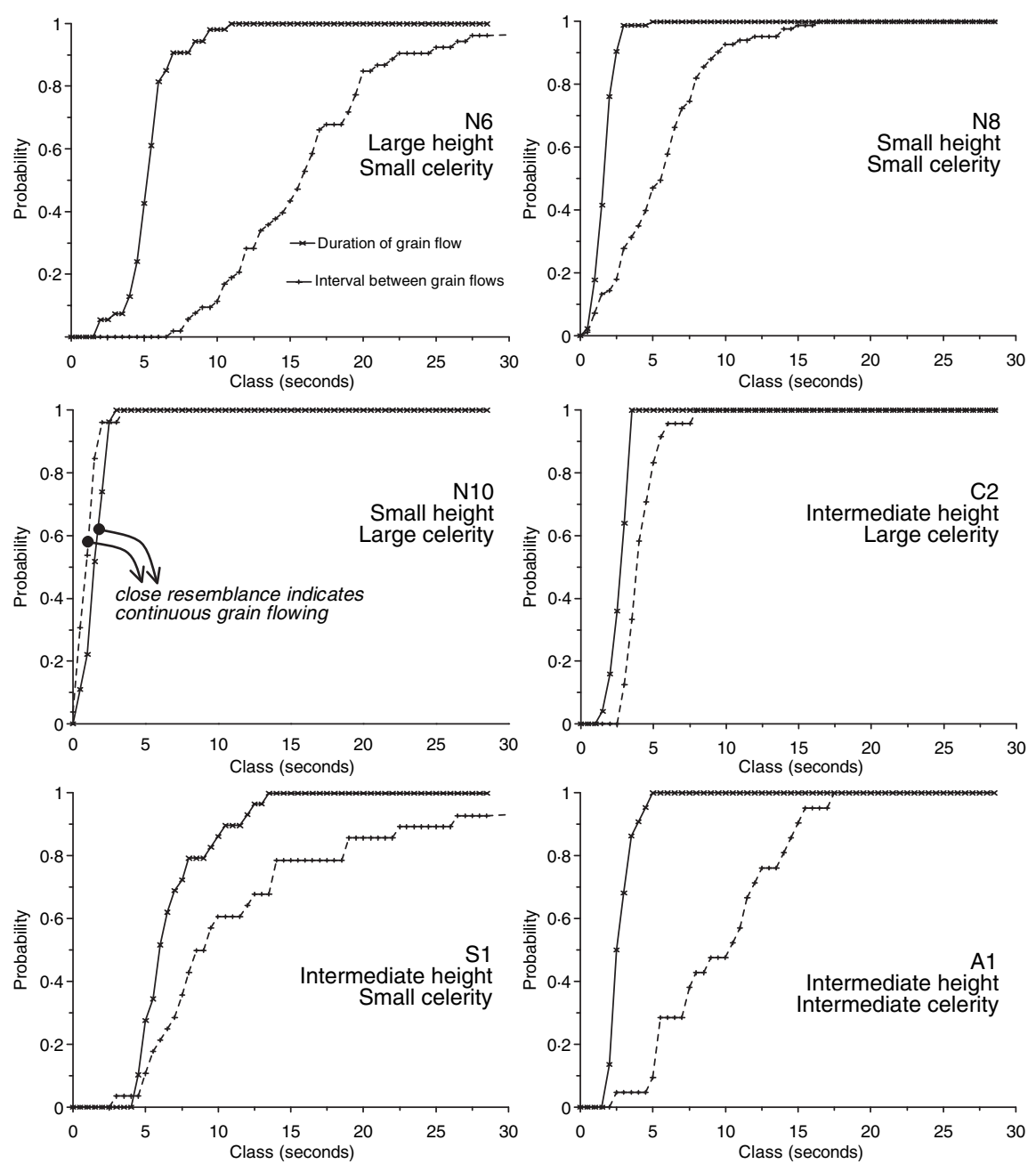

Fig. 9. Probability distributions of the duration of, and interval between grainflows for representative experiments. Generalized information on delta height and celerity is given in the panels. 
A

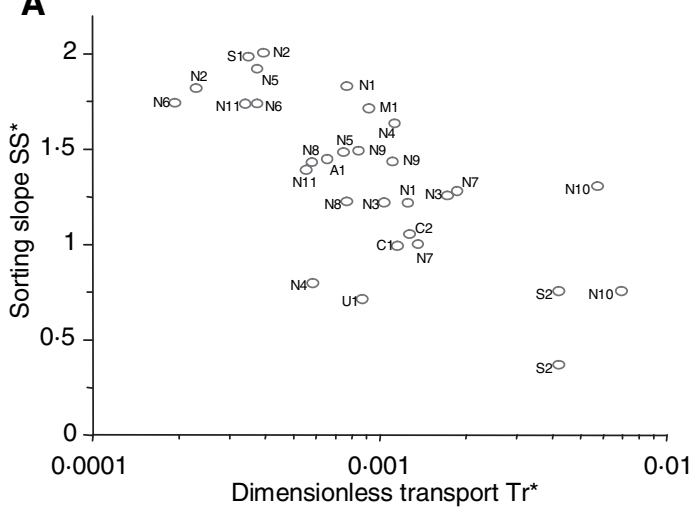

C

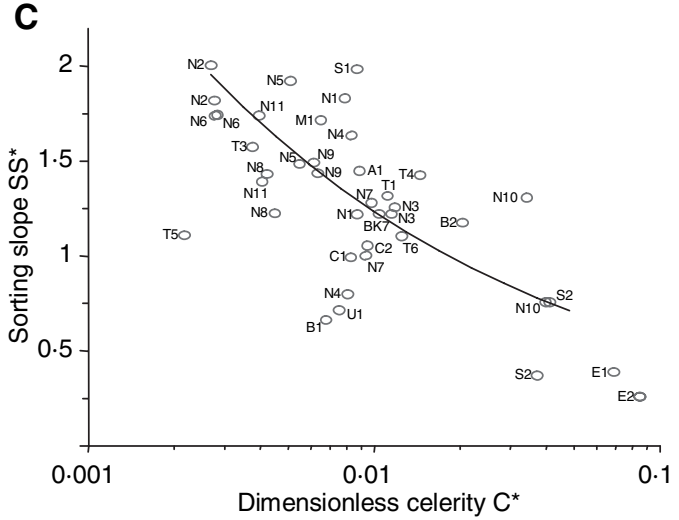

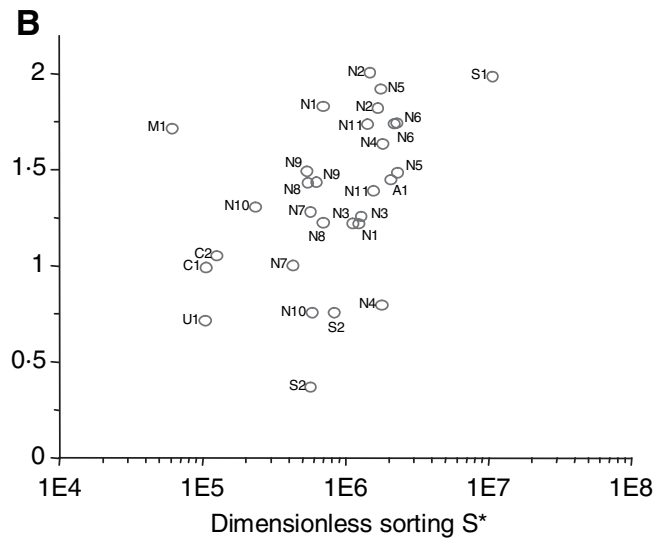

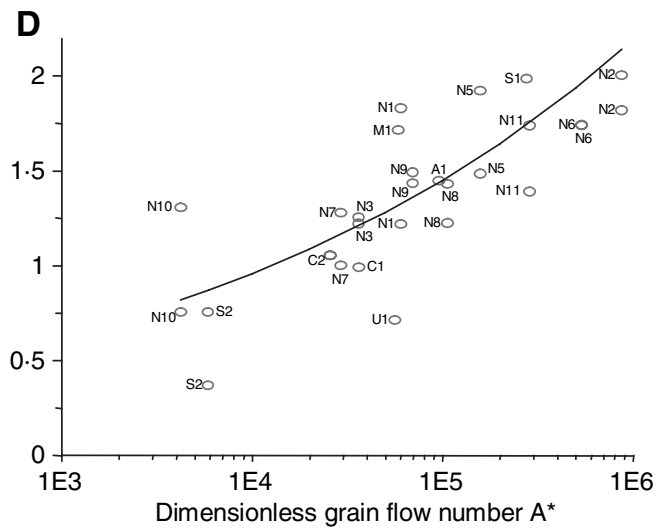

Fig. 10. Relation between dimensionless numbers and fining upward sorting. Sorting slope as computed from the data presented in Figs 6 and 7, versus the dimensionless celerity, transport and sorting numbers. The line in C and D shows the power functions of sorting slope versus $C^{*}$ or $A^{*}$ (see text). The $C^{*}$ panel includes data from literature (see Discussion).

Table 2. Correlations between the natural logarithm of the dimensionless parameters. The significance is determined with the $F$-test at a probability level of 0.05 for 30 data points, which gave a critical correlation of 0.36. Significant correlations are given in bold script.

\begin{tabular}{|c|c|c|c|c|c|c|c|}
\hline & $S^{*}$ & $\mathrm{Tr}^{*}$ & $C^{*}$ & $A^{*}$ & $G^{*}$ & $\mathrm{SS}^{*}$ & $\sigma_{g, \text { bottom }}$ \\
\hline$S^{*}$ & $1 \cdot 00$ & & & & & & \\
\hline $\operatorname{Tr}^{*}$ & $-0 \cdot 45$ & $1 \cdot 00$ & & & & & \\
\hline$C^{*}$ & $-0 \cdot 27$ & 0.92 & $1 \cdot 00$ & & & & \\
\hline$A^{*}$ & 0.52 & -0.96 & -0.94 & $1 \cdot 00$ & & & \\
\hline$G^{*}$ & $0 \cdot 19$ & $0 \cdot 42$ & $0 \cdot 56$ & $-0 \cdot 42$ & $1 \cdot 00$ & & \\
\hline $\mathrm{SS}^{*}$ & $0 \cdot 42$ & $-0 \cdot 56$ & $-0 \cdot 59$ & $0 \cdot 69$ & $-0 \cdot 26$ & $1 \cdot 00$ & \\
\hline$\sigma_{g, \text { bottom }}$ & $-0 \cdot 33$ & $0 \cdot 56$ & $0 \cdot 58$ & $-\mathbf{0} \cdot 61$ & $0 \cdot 34$ & 0.54 & $-1 \cdot 00$ \\
\hline
\end{tabular}

to obtain in active process environments so the regressed function of $\mathrm{SS}^{*}$ versus $C^{*}$ is given as well for practical purposes.

The sorting slopes $\mathrm{SF}_{i}{ }^{*}$ (Fig. 8C and D) demonstrate that the grain-size fractions behave in a complex way. In general there is a trend of increasing $\mathrm{SF}_{i}{ }^{*}$ with increasing relative grain size $\psi_{i}{ }^{*}$, but the trend is reversed for the finest fraction except for the U, M and S mixtures. It is not clear why the behaviour varies between the mixtures, but it discourages the construction of a simple vertical sorting model for grain-size fractions (discussed later).

The predictive capacity of the dimensionless celerity $C^{*}$ for vertical trends in average grain size should be reasonable. The relation with the grainflow number $A^{*}$ is given as well because its correlation was higher and for the sake of future work on cross-bedded deposits. In double logarithmic space, the sorting slope $\mathrm{SS}^{*}$ versus $C^{*}$ or $A^{*}$ is a straight line, so power functions were fitted:

$$
\begin{aligned}
& \text { (a) } \mathrm{SS}^{*}=-1 \cdot 4 C^{*-0 \cdot 35} \\
& \text { (b) } \mathrm{SS}^{*}=-1 \cdot 7 A^{* 0 \cdot 18}
\end{aligned}
$$

So the vertical sorting can now be computed as:

$$
\begin{aligned}
& \text { (a) } \psi_{Z^{*}}^{*}=\sigma_{a, T}\left[\left(1-z^{*}\right)-0 \cdot 5\right]-1 \cdot 4 C^{*-0 \cdot 35} \\
& \text { (b) } \psi_{Z^{*}}^{*}=\sigma_{a, T}\left[\left(1-z^{*}\right)-0 \cdot 5\right]-1 \cdot 7 A^{* 0 \cdot 18}
\end{aligned}
$$

The intercept $\left[\left(1-z^{*}\right)-0 \cdot 5\right]$ of the vertical sorting $\psi^{*}$ is thus simply taken at $z^{*}=0.5$ 
because this is the average intercept for the data presented in Figs 6 and 7, which means that the grain size at 0.5 times the delta height is equal to the grain size averaged over the delta.

The relation between the dimensionless numbers and the toeset deposition is shown in Fig. 11 and Table 2. The $\mathrm{C}$ experiments are outliers in all
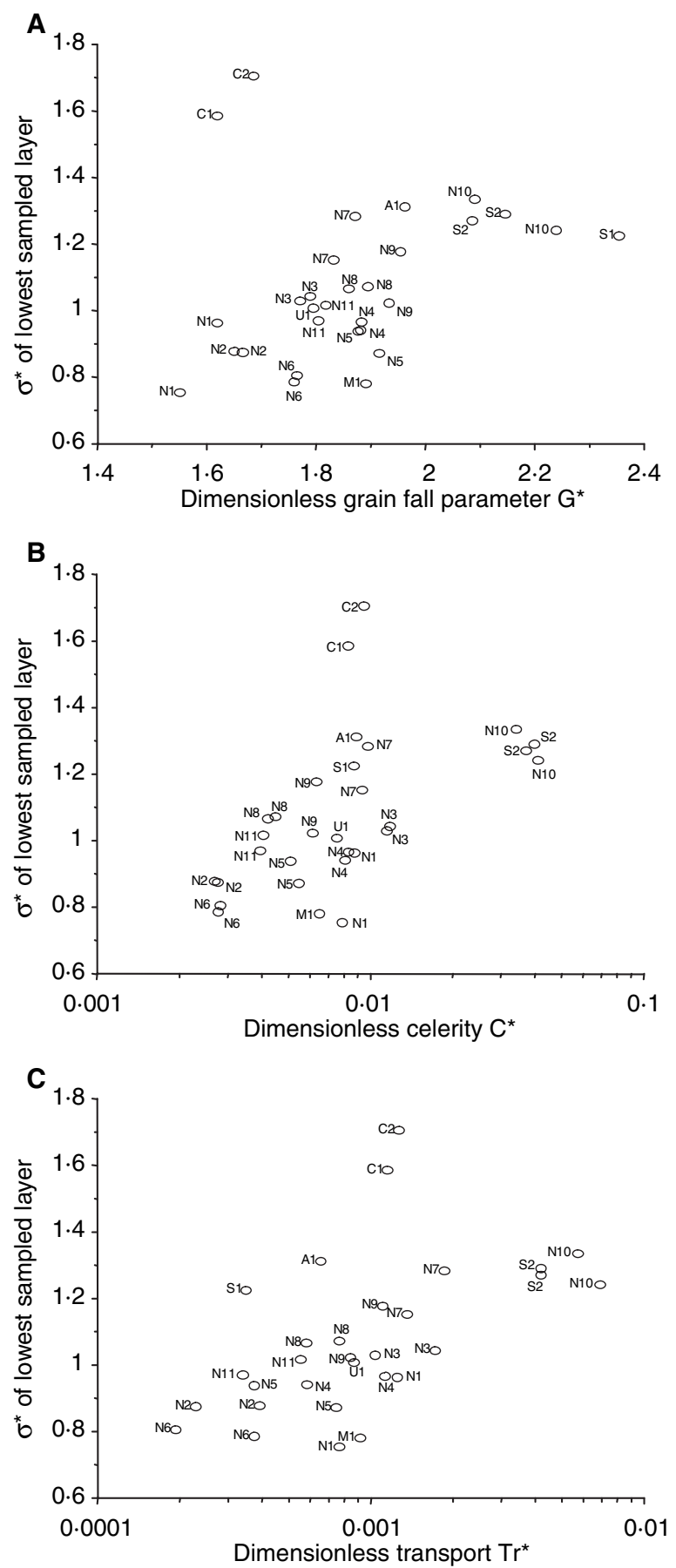

Fig. 11. The relative standard deviation of the toeset sediment $\left(\sigma^{*}\right)$ plotted versus the dimensionless celerity $C^{*}$ (A), (B) transport $\mathrm{Tr}^{*}$ and (C) grain fall $G^{*}$ numbers. graphs, which is expected because the fine sand in the bimodal sand-gravel mixture $\mathrm{C}$ was much more susceptible to suspension than the coarse sand in the N, A and S experiments. There is a weak relation between the sorting slope and the dimensionless grain fall parameter $\left(G^{*}\right)$, but $G^{*}$ is strongly correlated to $C^{*}$ and $\operatorname{Tr}^{*}$, making $G^{*}$ largely redundant.

\section{DISCUSSION}

\section{The processes of sorting}

For the first experimental series ( $\mathrm{N}$ sediments), three trends (apart from fining upward) in the sorting are manifest that confirm and extend the findings and hypotheses from the review section:

1. The given observations on the sorting process in grainflows agree with most records in literature (e.g. Bagnold, 1954; Allen, 1965; Jopling, 1965; Hunter \& Kocurek, 1986; Pye \& Tsoar, 1990; Makse, 1997; Koeppe et al., 1998; Tischer et al., 2001; Kleinhans, 2002). The observation that the sorting is established by drag of a large grainflow on the gravelly top of the underlying grainflow deposit confirms the hypothesis in the review section. The shearing plane of that large grainflow was at the transition between gravel and sand in the underlying grainflow deposit, which can be explained with the smaller angle of repose of that gravel on the sand being smaller than the angle of repose of the overlying sand on the underlying gravel (Makse, 1997). Sohn et al. (1997) mentions a comparable mechanism on a Gilbert type delta foreset in a Miocene fan delta: protruding large clasts are apt to be remobilized by new debrisflows (their fig. 8A) and large clasts were found to have a small resistance to the substrate and a larger momentum and therefore outrun further downslope (their fig. 8B).

2 . The relations of $\sigma^{*}$ versus $z^{*}$ are more curved in the middle of the delta for $\Delta>0 \cdot 1$ than for $\Delta<0 \cdot 1$ (Fig. 6). This means that the sediment is actually better sorted (smaller $\sigma^{*}$ ) in the top and lower parts of the larger deltas than in the middle of the larger deltas and the whole of the small deltas. So, for larger deltas, the sorting process is more efficient at the top and lower parts of the foreset. This is also the case for the S1 (large delta) and S2 (small delta) experiments. This can be interpreted as that the small deltas were too small to develop fully sorted lee slopes, whereas for $\Delta>0 \cdot 1$ the vertical patterns in standard deviation 
are similar indicating that these deltas were large enough for full development of the sorting.

3 . The toeset is more prominently present in the lowest deltas, the measured thickness (not shown here) also indicates this. So, the fine sediment settles from suspension on the flume base for the lowest deltas and settles on the lee slope of the higher deltas.

The second experimental series with various sediment mixtures (Fig. 7) reveals four additional observations:

4. The differences in sorting between all sediment mixtures are much larger than the differences in sorting for one mixture in various conditions. The mixtures with a smaller geometric standard deviation (M1 and U1) show less vertical sorting; the sorting trend in U1 is very small compared to that of wider mixtures. This was expected, because the more uniform the sediment, the less there is to sort. There are other differences between the mixtures, e.g. the contrast between M1 and U1 with other mixtures (Fig. 8D), that cannot be explained from the parameters.

5. When A1 is compared to the $\mathrm{N}$ series, it can be observed that the angularity of the coarser part of the A mixture has no significant effect on the sorting. The A and $\mathrm{N}$ sediment have comparable grain sizes and standard deviations, and the prominent difference is the angularity of the larger half of the grains.

6 . The toeset is much more strongly developed if the finest fraction is much finer than the rest of the sediment (fine tail or bimodal grain-size distribution) as in experiments C1 and C2. So, the flow conditions on the alluvial slope were such that the gravel in the mixture $\mathrm{C}$ could be transported as bedload, while the fine sand was suspended and deposited in a well-developed toeset.

7. The replica-experiments $\mathrm{C} 1$ and $\mathrm{C} 2$ were done in the same conditions, except that the flow discharge in C2 was 1.5 times as high as in C1, and the alluvial slope of $\mathrm{C} 2$ consequently was smaller while the flow velocity in C2 was $10 \%$ higher. The difference in sorting between C1 and $\mathrm{C} 2$, however is negligible, so the flow conditions on the alluvial slope in this range have a marginal effect on the sorting at the lee slope of the delta. This is not true, however, for the toeset formation in the $\mathrm{N}$ series; the flow discharge has an effect. For example, for experiment N10 the flow discharge was 1.6 times as high as in N8, and the toeset is much more developed in N10 than in N8, although the toeset is still only a few $\mathrm{mm}$ in thickness. So, the flow conditions on the alluvial slope have no obvious effect on the sorting on the foreset, but do have an effect on the toeset formation. This agrees with the visual observation that suspension at the brinkpoint was limited except in the deltas with the highest celerity (and transport rate, and flow velocity above the delta top).

\section{The effect of grainflow size and kinematics on vertical sorting}

Grainflow kinematics decrease vertical sorting (Fig. 9). In addition, the S1 experiment shows a much larger variation in $T_{g}$ than the other experiments. An explanation is related to the fact that S1 had much less gravel than the other sediments. For a large slope failure and grainflow in the $\mathrm{N}$ and $\mathrm{C}$ experiments to take place, the gravelly layer on the lower half of the slope had to fail. As a grainflow cannot become thinner than one grain thickness, this involves thick grainflows. In the S1 experiment such a strong gravelly surface layer was not present, and the slope could therefore fail sooner. Thus both frequent thin and infrequent thick grainflows became possible.

This explanation suggests that the grainflow dynamics are an effect rather than a cause of the vertical sorting. In the present case, $T_{g}$ depends mostly on the wedge volume which is itself constrained by the necessary force to mobilize the gravelly surface layer on the slope. This means that the sediment transport just upstream of the brinkpoint determines the $T_{g}$. Indeed, the grainflow frequency $f=1 / T_{f}$ strongly depends on the celerity $C^{*}$ (Fig. 12A). Consequently, the grainflows tend to become continuous with increasing $C^{*}$; that is, the ratio of grainflow duration and interval between subsequent grainflows $T_{g} / T_{f}$ approaches unity for the faster repetitions of grainflows (Fig. 12B).

The grainflow thickness $h_{g}$ was found to depend on the delta height (Fig. 12C). This confirms the findings of Allen (1970) and Hunter \& Kocurek (1986), and demonstrates that the present dataset is consistent with their results even though the data from the literature was obtained from dunes and the present from the deltas. However, the laminae thickness of foreset deposits cannot be used for reconstruction of the delta height, because the dataset (Fig. 12C) is for small deltas and dunes and shows much scatter, and it can reasonably be suspected that the laminae thickness depends on grain size as well. 

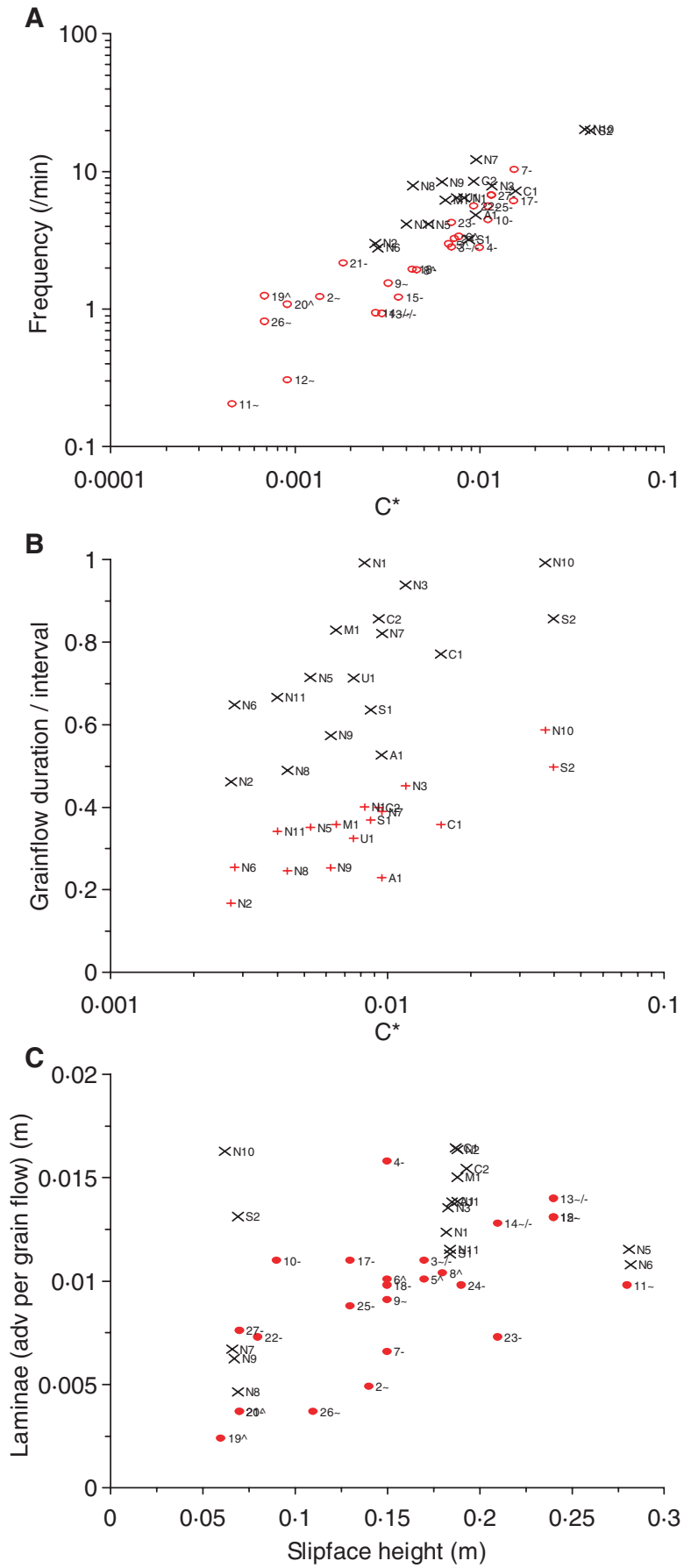

Fig. 12. (A) Frequency as a function of dimensionless celerity $C^{*}$. Numbers and symbols denote their experiment numbers and bed states on top of their dunes $(\sim$ : ripples, $\wedge$ : secondary dunes, -: upper plane bed). (B) Ratio of grainflow duration and interval between subsequent grainflows $T_{g} / T_{f}$ as a function of $C^{*}$ [+: computed as $T_{g} / T_{f}$, x: computed as the more extreme case with $\left(T_{g}+\sigma_{T_{g}}\right) /\left(T_{f}-\sigma_{T_{f}}\right]$, where $\sigma=$ standard deviation). When the ratio approaches unity, the grainflowing becomes continuous. (C) Laminae thickness (grainflow thickness) versus slipface height (delta height) of the present data and those of Hunter \& Kocurek (1986).

\section{Towards fractionwise prediction of vertical sorting}

The sorting model developed above could be modified to compute the vertical distribution of grain-size fractions by integrating (4):

$$
\frac{P_{i, z}}{P_{i, T}}=\left[\left(1-z^{*}\right)-0 \cdot 5\right] S F_{i}^{*}
$$

where $\mathrm{SF}_{i}{ }^{*}$ is a function of $\psi_{i}^{*}$ and $C^{*}$ according to Fig. 8. However, in this approach it would be assumed that the fractions are linearly distributed with increasing and decreasing abundance in $z^{*}$ for fine and coarse fractions, respectively. Figure 8 demonstrates, however, that this assumption is violated for the $\mathrm{N}$ mixture. Moreover, the relation between the $\mathrm{SF}_{i}{ }^{*}$ and $\psi_{i}^{*}$ depends on the characteristics of the sediment mixture, which means that a simple function may give errors. For the modelling of vertical sorting a non-linear function, depending on undefined mixture characteristics would be needed, which in addition conserves mass for all grain-size fractions. Unfortunately there is not enough data available now to undertake such a task.

\section{Applicability of the results to natural river dunes}

The performance of Eq. 11a was tested against the data of the experiments. The results (Fig. 13A) agree with the $\mathrm{N}$ data (Fig. 6) although the scatter is a factor of 2 . The ratio of predicted and fitted $\mathrm{SS}^{*}$ for all available data (Fig. 13B) demonstrates that $95 \%$ of the slopes are predicted within a factor of 2 for various datasets. For verification in the case of sorting in dunes and bars (discussed later), the vertical sorting slope $\mathrm{SS}^{*}$ as a function of $C^{\star}$ is also computed for the data of Termes (1986), Blom \& Kleinhans (1999), Blom et al. (2000), and Kleinhans (2002). For these data the scatter is larger, in specific for larger $C^{*}$ and $\sigma_{a, T}$ (Fig. 13C), but in general Eq. 11a predicts the sorting well. The computations with $A^{*}$ have the same predictive capacity for the experiments but cannot be done for the data from the literature.

It is concluded that the sorting process is mostly dependent on $C^{*}$ and the sediment mixture characteristics, but that the natural variation is large. The variation is due to the variables that were not included in the dimensional analysis; notably, the mixture characteristics are not fully described with the mean grain size and standard deviation alone (Fig. 8D). In addition, the sorting 

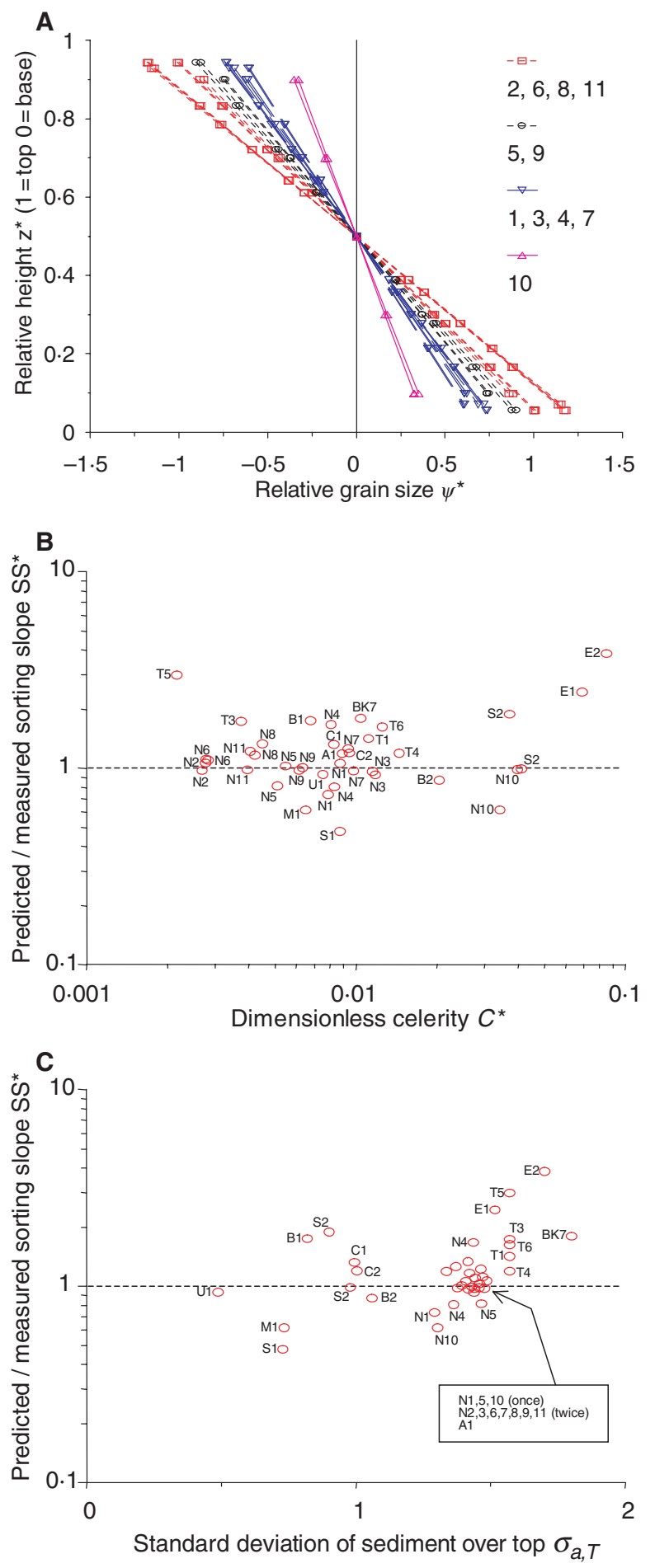

Fig. 13. Sorting model performance. (A) Predicted vertical sorting based on $C^{*}$ (Eq. 11a); compare to Fig. 6. The $\mathrm{N}$ experiments are grouped for comparable celerities (experiment numbers given in the legend). (B) Ratio of predicted and measured SS* (Eq. 11a) including data from literature (see text), plotted as a function of $C^{*}$. For perfect prediction the ratio should be 1. (C) Same as (B), now plotted as a function of $\sigma_{a, T}$. is the result of two simultaneous processes with different variables: the grain fall process mainly depends on the flow conditions and mode of sediment transport (bedload or suspended load) of the grain sizes on top of the delta, whereas the grainflow process mainly depends on the sediment transport rate, slip face height and the sediment characteristics that determine the grainflow thickness and rate of failure. To assess the applicability of the present results to natural lee slopes, the question of whether additional parameters such as dimensionless shear stress require consideration is addressed in the section on applicability to natural river dunes.

The applicability of the present results to river dunes is tested by comparison of the experimental ranges of flow conditions and celerity with those on experimental and field data from literature [Table 3, see Kleinhans (2004) for a complete description]. The comparison of the (suspended) grain fall conditions is based on the dimensionless shear stress and the median or mean grain size of the sediment in the bedforms (Fig. 14A and $\mathrm{B}$ ). The comparison of the grainflow conditions is based on the dimensionless celerity $C^{*}$ and on the ratio of grain size over delta or dune height (Fig. 14C and D).

The dimensionless shear stresses and grain sizes of the experiments presented here are usually in the range of the field and flume data from the literature. The celerities of the experiments are somewhat lower than the range of field and flume data. The conditions of the Calamus sand bed river are just below the criterion for suspension (Fig. 14), which means that an increase of shear stress will not lead to an increase of dune celerity but to the suspension of sediment that previously moved with the dunes as bedload. Therefore, in the sand bed rivers the dimensionless celerity cannot become much larger than observed in the Calamus river. It is expected that sandy gravel-bed rivers have the largest potential for vertical sorting, as the standard deviation of the sediment is the largest while conditions are not too near suspension of the finer fractions. In general, the conditions in rivers are rather well represented by the sorting data presented herein.

Finally, the sorting in the lee of deltas is similar to the sorting in the lee of dunes except for the toeset. The main difference between foreset sorting in deltas and dunes is that the relative standard deviation $\sigma^{*}$ of the dune shows a much stronger increase with depth than in the $\mathrm{N}$ experiments (Fig. 15, compare to Figs 6 and 7). This may be because the sediment sorting in the 
Table 3. Description of the datasets used in the comparison between the experiments presented here, experiments in literature and three field datasets ranging between sand-bed and gravel-bed rivers.

\begin{tabular}{|c|c|c|c|c|c|c|c|c|}
\hline Author & Code* & Condition & $\begin{array}{l}\text { Grain } \\
\text { size } \\
\left(D_{50}, \mathrm{~mm}\right)\end{array}$ & $\begin{array}{l}\text { Flow } \\
\text { depth }^{\dagger} \\
(\mathrm{m})\end{array}$ & $\begin{array}{l}\text { Flow } \\
\text { velocity } \\
\left(\mathrm{m} \mathrm{sec}^{-1}\right)\end{array}$ & $\tau^{* \dagger}(-)$ & $\begin{array}{l}\text { Bedform } \\
\text { height (m) }\end{array}$ & $\begin{array}{l}\text { Bedform } \\
\text { celerity } \\
\left(\mathrm{cm} \mathrm{min}{ }^{-1}\right)\end{array}$ \\
\hline Gabel (1993) & $\mathrm{C}$ & Calamus & $0 \cdot 25-0 \cdot 41$ & $0 \cdot 34-0 \cdot 61$ & $0 \cdot 47-0 \cdot 77$ & $0 \cdot 46-0 \cdot 88$ & $0 \cdot 097-0 \cdot 195$ & $1 \cdot 2-2 \cdot 4$ \\
\hline Dinehart (1992) & NT & North Toutle r. & $22 \cdot 2-36$ & $1 \cdot 4-2 \cdot 24$ & $2 \cdot 14-2 \cdot 74$ & $0 \cdot 1-0 \cdot 24$ & $0 \cdot 143-0 \cdot 41$ & $67 \cdot 2-255$ \\
\hline Kleinhans (2002) & $\mathrm{R}$ & Rhine river & $1 \cdot 58-1 \cdot 58$ & $8 \cdot 6-10 \cdot 69$ & $1 \cdot 42-1 \cdot 86$ & $0 \cdot 33-0 \cdot 74$ & $0 \cdot 11$ & $4 \cdot 2-14 \cdot 4$ \\
\hline $\begin{array}{l}\text { Blom \& Kleinhans } \\
\text { (1999) }\end{array}$ & $\mathrm{BK}$ & Dunes in flume & $0 \cdot 59-0 \cdot 73$ & $0 \cdot 19-0 \cdot 35$ & $0 \cdot 59-0 \cdot 79$ & $0 \cdot 14-0 \cdot 37$ & $0 \cdot 011-0 \cdot 057$ & $5 \cdot 4-7 \cdot 8$ \\
\hline Blom et al. (2000) & $\mathrm{B}$ & Dunes in flume & $1 \cdot 34-1 \cdot 34$ & $0 \cdot 16-0 \cdot 32$ & $0 \cdot 63-0 \cdot 82$ & $0 \cdot 13-0 \cdot 21$ & $0 \cdot 024-0 \cdot 062$ & $6-18$ \\
\hline Termes (1986) & $\mathrm{T}$ & Bar in flume & $0 \cdot 64-0.96$ & $0 \cdot 17-0 \cdot 21$ & $0 \cdot 69-1 \cdot 2$ & $0 \cdot 15-0 \cdot 43$ & $0 \cdot 08-0 \cdot 1$ & $1 \cdot 2-9 \cdot 6$ \\
\hline Kleinhans (2002) & $\mathrm{K}$ & Dunes in flume & $1 \cdot 12-1 \cdot 56$ & $0 \cdot 13-0 \cdot 21$ & $0 \cdot 78-1 \cdot 08$ & $0 \cdot 24-0 \cdot 25$ & $0 \cdot 018-0 \cdot 035$ & $55 \cdot 8-81$ \\
\hline
\end{tabular}

* The code of the dataset as used in Fig. 12.

${ }^{\dagger}$ Average flow parameters, for Termes the flow parameters above the bar.
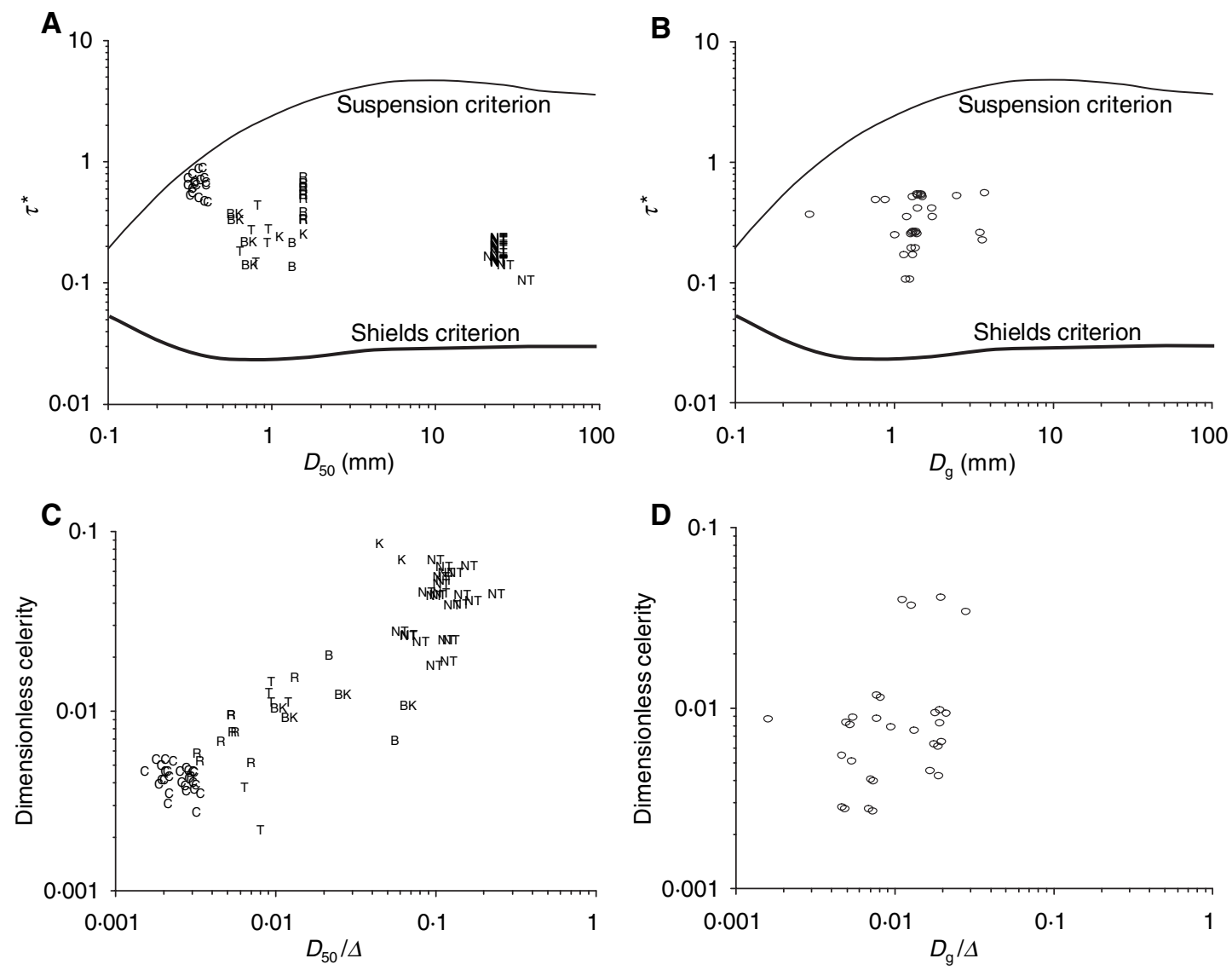

Fig. 14. Comparison between field and experimental datasets from literature with the experiments presented here. (A, B) Sediment mobility. The Shields criterion for incipient sediment motion and the Bagnold suspension criterion are indicated. (C, D) Dune parameters. (A, C) Datasets summarized in Table 3. (B, D) Experiments presented in this paper.

grainflows at the lee side of the dunes is affected by the stronger counterflow between dunes. Yet the vertical sorting is reasonably well predicted with Eq. 11a within its limitation of linearity, indicating that additional parameters such as dimensionless shear stress are not necessary. In addition, no toesets were found in the experi- ments with dunes of Blom \& Kleinhans (1999). This is explained by the difference in flow structure over deltas and dunes. Over deltas, there is uniform flow over the top of the delta and then a sudden and large increase of the water depth in which the flow velocity reduces to almost zero. Over dunes the flow expansion is 

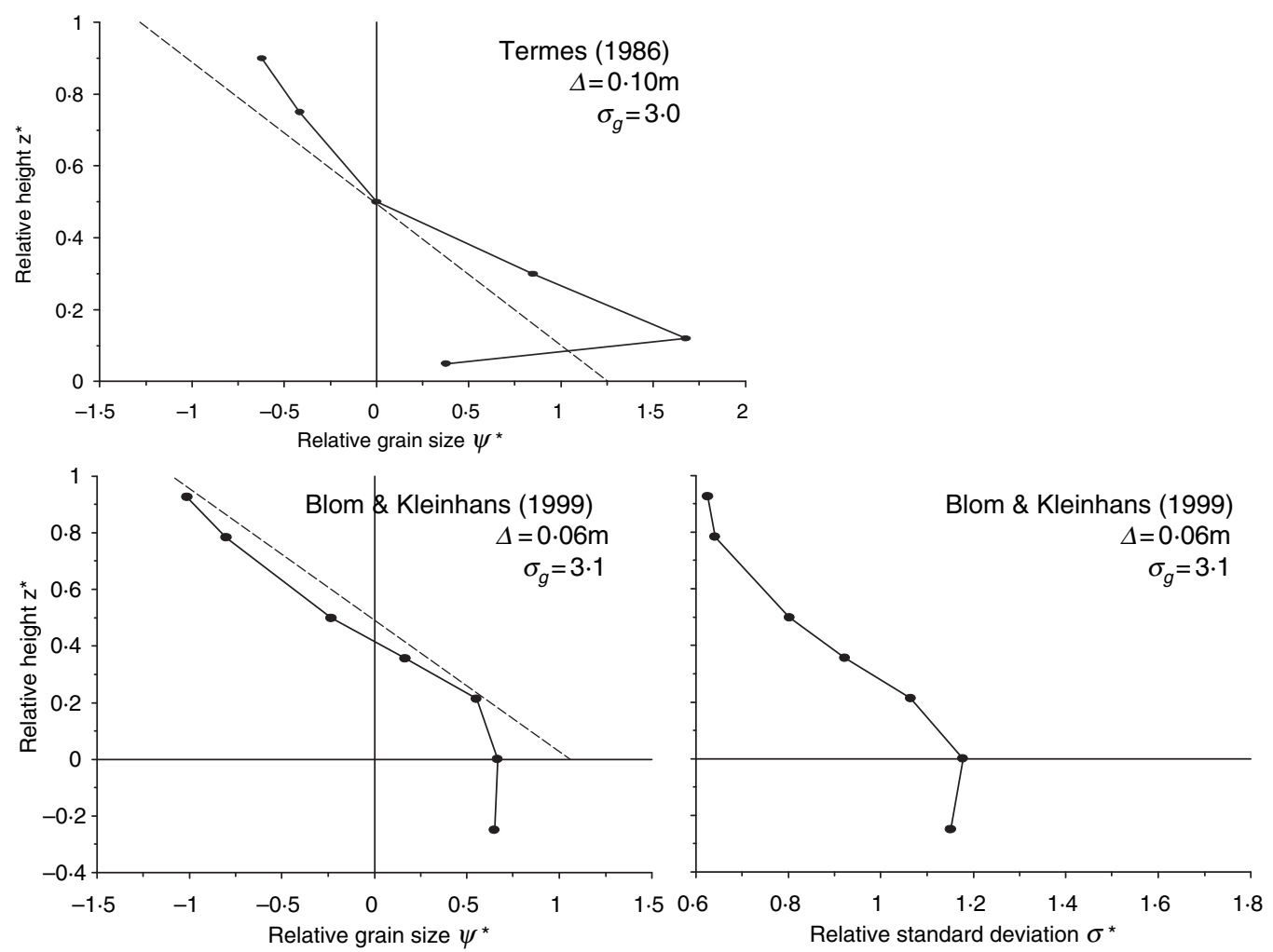

Fig. 15. Examples of vertical sorting in experiments reported in literature, plotted in the same way as Figs 6 and 7 for comparison. The celerity is within a factor of 2 that of the N1-N9 experiments, and the height is comparable with that of the N7-N9 experiments. The geometric standard deviation of the sediment is slightly larger than in the N experiments. The Termes data is from a bar in a flume, and the Blom \& Kleinhans (1999) data from dunes in a flume. The dashed line is the prediction by Eq. 11 a.

much less extreme because the water depth over dunes is much larger than over deltas. As a consequence, the turbulent flow structure at the lee side of the deltas and dunes differ. McLean \& Smith (1986) found that the counterflow at the lee side of backward steps is much weaker and extends further downstream than that at the lee side of dunes, while the turbulence intensity at the lee side of periodic dunes was found to be much stronger than for single backward steps. Increased turbulence intensity decreases grain fall from suspension. Consequently, the grain fall and toeset deposition is less or absent in dunes and counterflow affecting the foreset is stronger between dunes.

\section{CONCLUSIONS}

The fining upward sorting trend in the deposits of deltas was studied by systematic experimentation and dimensional analysis with various sediment mixtures. The results were found to be applicable to dunes and bars. The fining upward trend is caused by a three-stage sediment sorting process on the lee side of the delta. (i) Sediment arriving at the top of the delta is deposited from grain fall on the upper lee slope. This mass of sediment moves downslope in grainflows. (ii) In small grainflows, the gravel is worked to the top of the flow by kinetic sieving. (iii) Large grainflows have their shearing plane at the transition from the gravel to the underlying sand, and drags the gravel downslope which leads to a fining upward trend. In addition, the finest sediment deposition from grain fall may take place downstream of the delta, leading to a toeset that is preserved as a bottomset below the migrating delta.

Two factors determine the vertical sorting: the mixture characteristics and the delta celerity or laminae thickness. The efficiency of the sorting process in the experimental deltas mainly depends on the grain-size distribution: if the sediment mixture is very wide, then the sorting is better developed than when the mixture is almost uniform. If the mixture is bimodal or fine-tailed, however, the finest sediment is likely transported in suspension and settles out on the lee side and toe of the delta as a toeset. A larger celerity of the delta front leads to a decreased efficiency of sorting. 
Dimensionless functions have been developed for prediction of vertical sorting from the mixture standard deviation and the celerity or the laminae thickness of deposited grainflows. These functions reproduce the sorting in experimental bars and dunes reported in the literature. The data demonstrate a non-linear response of the finest and coarsest size-fractions and structural differences between mixtures that could not be related to average grain size or mixture standard deviation. This is explained by the interaction between the grainflow and grain fall process.

\section{ACKNOWLEDGEMENTS}

I thank Gary Parker for inviting me to St Antony Falls Laboratory and making these experiments possible, for teaching me to think in nondimensional numbers and for many stimulating discussions. I thank Jeffrey Marr for making the experiments possible. Benjamin Erickson provided the digital videos. I thank all those who helped with flume modifications and the sieve samples. The discussions with Suzanne Leclair, Chris Paola, James Kakalios, Astrid Blom and Janrik van den Berg were appreciated. The comments by reviewers Stephen Rice, Marwan Hassan and Paul Carling improved the manuscript. The investigations were supported by the Netherlands Earth and Life sciences Foundation (ALW) with financial aid from the Netherlands Organization for Scientific Research (NWO), and by the St Anthony Falls Laboratory. Please contact the author to obtain the full dataset in digital format.

\section{NOMENCLATURE}

$A^{*} \quad$ Dimensionless grainflow number

$C \quad$ Celerity of lee slope

$C^{*} \quad$ Dimensionless celerity

df Degrees of freedom

$D_{g} \quad$ Geometric mean grain size

$f \quad$ Frequency of grainflows

$g \quad$ Gravitational acceleration

$G^{*} \quad$ Dimensionless grain fall number

$h_{0} \quad$ Basin water depth

$h_{1} \quad$ Water depth on top of the delta

$h_{g} \quad$ Immobilized grainflow thickness (perpendicular to lee slope)

i Water surface slope

$L \quad$ Progradation length of delta

n Number

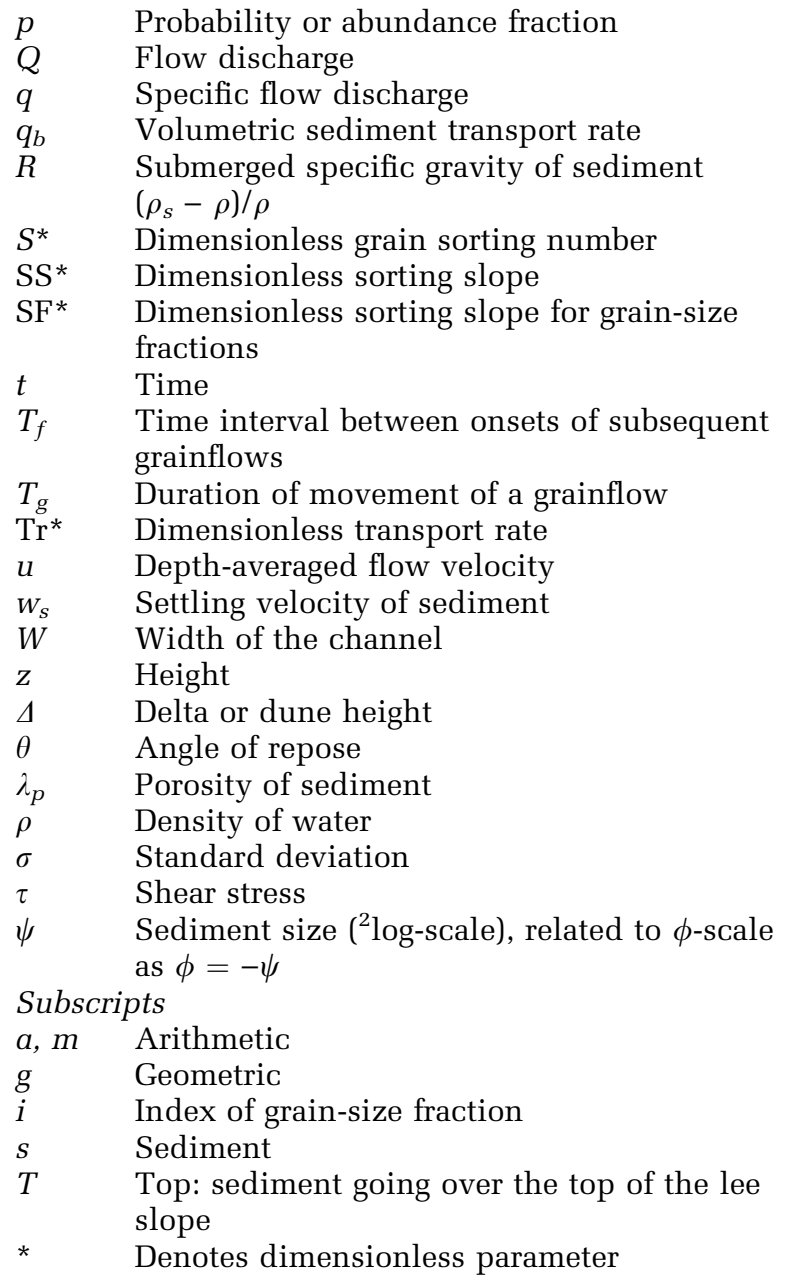

\section{REFERENCES}

Allen, J.R.L. (1965) Sedimentation to the lee of small underwater sand waves: an experimental study. J. Geol., 73, 95116.

Allen, J.R.L. (1970) The avalanching of granular solids on dune and similar slopes. J. Geol., 78, 326-351.

Allen, J.R.L. (1984) Sedimentary Structures, Their Character and Physical Basis. Developments in Sedimentology. Elsevier, Amsterdam, The Netherlands, $30 \mathrm{pp}$.

Bagnold, R.A. (1954) Experiments on a gravity-free dispersion of large solid spheres in a Newtonian fluid under shear. Proc. Roy. Soc. London, A225, 49-63.

Blom, A. and Kleinhans, M.G. (1999) Non-uniform Sediment in Morphological Equilibrium Situations. Data Report Sand Flume Experiments 97/98. University of Twente, Rijkswaterstaat RIZA, WLIDelft Hydraulics, University of Twente, Civil Engineering and Management, The Netherlands.

Blom, A., Ribberink, J.S. and Van der Scheer, P. (2000) Sediment transport in flume experiments with a trimodal sediment mixture. In: Proceedings of the Gravel Bed Rivers Conference 2000 (Eds T. Nolan and C. Thorne), 28 August-3 September, New Zealand, Special public. CD-ROM of the 
New Zealand Hydrological Society (http://www.geog. canterbury.ac.nz/services/carto/toc.htm).

Brush, L.M. (1965) Sediment sorting in alluvial channels. In: Primary Sedimentary Structures and Their Hydrodynamic Interpretation (Ed. G.V. Middleton), SEPM Spec. Publ., 12, 25-33.

Dinehart, R.L. (1992) Evolution of coarse gravel bed forms: field measurements at flood stage. Water Resour. Res., 28, 2667-2689.

Gabel, S.L. (1993) Geometry and kinematics of dunes during steady and unsteady flows in the Calamus River, Nebraska, USA. Sedimentology, 40, 237-269.

Hunter, R.E. (1985a) Subaqueous sand-flow cross strata. J. Sed. Petrol., 55, 886-894.

Hunter, R.E. (1985b) A kinematic model for the structure of lee-side deposits. Sedimentology, 32, 409-422.

Hunter, R.E. and Kocurek, G. (1986) An experimental study of subaqueous slipface deposition. J. Sed. Petrol., 56, 387394.

Jopling, A.V. (1965) Laboratory study of the distribution of grain sizes in cross-bedded deposits. In: Primary Sedimentary Structures and Their Hydrodynamic Interpretation (Ed. G.V. Middleton), SEPM Spec. Publ., 12, 53-65.

Julien, P.Y., Lan, Y. and Berthault, G. (1993) Experiments on stratification of heterogeneous sand mixtures. Bull. Soc. Geol. Fr., 164, 649-660.

Kleinhans, M.G. (2002) Sorting Out Sand and Gravel; Sediment Transport and Deposition in Sand-Gravel Bed Rivers. Netherlands Geographical Studies 293, Royal Dutch Geographical Society, Utrecht, The Netherlands, 317 pp.

Kleinhans, M.G. (2004) Sorting in grainflows at the lee-side of dunes: review. Earth Sci. Rev., 65, 75-102. doi:10.1016/ S0012-8252-(03)00081-3.

Koeppe, J.P., Enz, M. and Kakalios, J. (1998) Phase diagram for avalanche stratification of granular media. Phys. Rev. E, 58, 4104-4107.
Love, D.W., Gutjahr, A. and Robinson-Cook, S. (1987) Location-dependent sediment sorting in bedforms under waning flow in the Rio Grande, Central New Mexico. In: Recent Developments in Fluvial Sedimentology (Ed. F.G. Ethridge, R.M. Flores and M.D. Harvey), pp. 37-47. Society of Economic Paleontologists and Mineralologists, Tulsa, OK, USA.

Makse, H.A. (1997) Stratification instability in granular flows. Phys. Rev. E, 56, 7008-7016.

McLean, S.R. and Dungan Smith, J. (1986) A model for flow over two-dimensional bed forms. J. Hydraul. Eng., 112, 300317.

Mohrig, D. and Dungan Smith, J. (1996) Predicting the migration rates of subaqueous dunes. Water Resour. Res., 32, 3207-3217.

Parker, G., Paola, C. and Leclair, S. (2000) Probabilistic Exner sediment continuity equation for mixtures with no active layer. J. Hydraul. Eng., 126, 818-826.

Pye, K. and Tsoar, H. (1990) Aeolian Sand and Sand Dunes. Unwin Hyman Ltd, London, UK, 396 pp.

Ribberink, J. (1987) Mathematical Modelling of One-dimensional Morphological Changes in Rivers with Non-uniform Sediment. Delft University, The Netherlands.

Sohn, Y.K., Kim, S.B., Hwang, I.G., Bahk, J.J., Choe, M.Y. and Chough, S.K. (1997) Characteristics and depositional processes of large-scale gravelly Gilbert-type foresets in the Miocene Doumsan fan delta, Pohang Basin, SE Korea. J. Sed. Res., 67, 130-141.

Termes, A.P.P. (1986) Vertical Composition of Sediment in a Dune. WL I Delft Hydraulics, Delft, R657-XXX, 14.

Tischer, M., Bursik, M.I. and Pitman, E.B. (2001) Kinematics of sand avalanches using particle-image velocimetry. J. Sed. Res., 71, 355-364.

Manuscript received 26 August 2003; revision accepted 9 December 2004 